\title{
Methodology for predicting brake squeal propensity using complex eigenvalue analysis, including thermo-mechanical effects
}

\author{
Marko Tirovic $^{a^{*}}$, Michele Vianello $^{a}$, Paul Bannister ${ }^{\mathrm{b}}$ \\ a School of Aerospace, Transport and Manufacturing, Cranfield University, \\ College Road, Cranfield, MK43 0AL, United Kingdom \\ b Jaguar Land Rover, Abbey Road, Whitley, Coventry, CV3 4LF, United Kingdom \\ *Corresponding author: m.tirovic@cranfield.ac.uk
}

\begin{abstract}
With brake squeal being most prevalent Noise Vibration and Harshness (NVH) issue in modern vehicles, this paper presents an improved methodology for brake squeal propensity prediction at the design stage. The research established four clearly defined "Stages" in conducting Finite Element (FE) squeal analyses, describing crucial input data, modelling procedures, outputs and results validations. Stage 1 deals with freefree modal characteristics of individual brake components and their material characteristics. Stage 2 combines individual parts, conducting Brake Assembly Mechanical FE Analyses. Stage 3 concentrates on fully Coupled Thermo-mechanical FE Analyses, and the concluding Stage 4 focuses on Brake Assembly Stability Analyses. Validations proved that very accurate predictions are possible, but the geometries, material characteristics and established modelling procedures must be strictly followed. Material characteristics were most prone to introduce discrepancies with measured values. 'Generic' values are found to be unacceptable and conducting own measurements was necessary, in particular for the friction material, whose anisotropic properties have been measured in detail, leading to high accuracy in predicting pad natural modes and frequencies. In Stage 4 the stability analyses of the full brake assembly were based on the Complex Eigenvalue Analysis (which included thermal aspects), with the sign of the real part giving an indication of stability and the imaginary part defining the frequency of the unstable mode. Instabilities and frequencies predicted match well with the values measured in dynamometer tests, clearly demonstrating the influence of thermal effects. The final output of the procedures described in this Paper is a validated 3D thermo-mechanical FE NVH brake assembly model in which natural frequencies and modes, instabilities and contributing factors can be predicted at any time during a brake application.
\end{abstract}

Keywords: Brake Squeal, Natural Frequencies, Thermal Effects, Digital Image Correlation, Pressure Sensitive Paper, Eigenvalue Analysis 


\section{NOMENCLATURE}

$\begin{array}{lll}\text { Symbol } & \text { Description } & \text { Unit } \\ \text { C } & \text { Elastic matrix } & \mathrm{Pa} \\ \mathrm{E} & \text { Young's Modulus } & \mathrm{Pa} \\ \mathrm{f} & \text { Frequency } & \mathrm{Hz} \\ \mathrm{ID} & \text { Inner Diameter } & \mathrm{mm} \\ \mathrm{m} & \text { Mass of the vehicle } & \mathrm{kg} \\ \mathrm{OD} & \text { Outer Diameter } & \mathrm{mm} \\ \mathrm{p}_{\mathrm{h}} & \text { Hydraulic pressure } & \mathrm{bar} \\ \mathrm{t} & \text { Time } & \mathrm{s} \\ \mathrm{t}_{\mathrm{a}} & \text { Duration of brake application } & \mathrm{s} \\ \mathrm{T} & \text { Temperature } & { }^{\circ} \mathrm{C} \\ \mathrm{V} & \text { Vehicle speed } & \mathrm{m} / \mathrm{s} \\ \varepsilon & \text { Strain } & \\ v & \text { Poisson ratio } & \\ \omega_{\mathrm{i}} & \text { Natural frequency of mode } i & \mathrm{~Hz} \\ \sigma & \text { Stress } & \mathrm{Pa}\end{array}$

\section{Introduction}

Even after a century of developing road vehicle brake systems, disc brake squeal remains an 'unresolved problem', Kinkaid et al. [1]. Considerable progress has been made resulting from substantial research on brake squeal conducted in the last several decades, using theoretical (analytical), experimental and numerical techniques. Still, the approach remains fragmented, related to specific designs and problems, heavily reliant on testing. The solutions are often 'fixes' applied to the brake components after much of the structural and thermal brake development work has been completed. The complexity of brake squeal prediction and elimination comes from the very design of the brake, its geometrical and material characteristics. Most importantly, brake operation is based on dry friction to develop braking torque, a very complex process with many influencing factors. Brake applications can largely vary in terms of speed, actuating pressure and temperatures. Furthermore, the components, in particular pads and disc wear, their interface contacts continuously change and geometries are modified at bulk scale too.

No precise definition of brake squeal has gained complete acceptance, but it is "a sustained high frequency vibration of brake system components during a braking action resulting in noise audible to vehicle occupants or passers-by", Kinkaid et al. [1]. It is a phenomenon of dynamic instability that occurs at one or more of the natural frequencies of the brake assembly, and it is independent from the rotor speed. The source of the noise is the frictional interaction between the pad and disc. 
Brake squeal is often subdivided into:

- High frequency squeal $(4-16 \mathrm{kHz}) \rightarrow$ Pads and rotor coupling has major impact on it;

- Low frequency squeal $(1-3 \mathrm{kHz}) \rightarrow$ Typically involves caliper, anchor bracket, knuckle and suspension, in addition to pads and rotor;

Occurrence is intermittent or even random. Some of the published research most applicable to the phenomenon studied will be analysed in more detail.

Analytical studies have provided useful insights into how friction laws, geometry, and the dynamics of brake components can lead to squeal or instability in simple models of disc brakes. The first model by Mills [2] established the variation in the friction coefficient with sliding velocity as the cause of brake squeal. The drop in kinetic friction with increased sliding velocity could lead to a stick-slip condition and produce self-excited vibration. Accordingly to, Spurr [3], the 'sprag-slip' theory, brake squeal was caused by the characteristics of the contact geometry between pads and disc. Squeal was only generated when this contact strip is sufficiently close to the leading edge of the pad, while was ameliorated when it was moved toward the trailing edge. This phenomenon was subsequently correlated in 'cantilever-on-disc' systems by Jarvis and Mills [4] and by Earles [5] in 'pin on disc' system. The common conclusions of these models are that brake squeal can be caused by geometrically induced instabilities that do not require variations in the coefficient of friction. The first researcher to consider brake squeal as a self-excited vibration induced by friction forces, with constant coefficient of friction, was North [6]. He emphasised the importance of coupling, introducing the 'binary flutter' theory, which is the existence of 'pair' or 'doublet' modes of vibration: Two modes of vibration which are very close together in terms of resonant frequency, but are out of phase by $90^{\circ}$. Transfer of energy between the 2 modes drives the binary flutter mechanism which leads to squeal. 'Splitting' the pair modes is regarded as an important principle for quiet brake rotor design. From the beginning, the models for squealing disc brakes have featured an increased number of degrees of freedom, higher complexity, and, often, more elaborate friction models.

Experimental approaches have been very useful in measuring unstable frequencies and modes of the brake assembly in operating conditions and investigating the effects of brake parameters and environmental factors on the squeal propensity. A considerable amount of experimental work is presented in literature, which can be divided in two categories: vibration-based and tribology-based. Accelerometers provide an effective tool for determining the vibration mode shapes and the forced response of a system. Unfortunately, they can only be used for analysis of stationary (not rotating) brake components (i.e. pads and caliper) making it almost impossible to determine the mode shapes of a squealing brake rotor. Optical techniques have been used more recently, such as Double Pulsed Laser Holographic Interferometry (Felske et al., [7], Fieldhouse and Newcomb [8]). The advantage is that the mode shapes of a brake rotor can be determined while it is squealing and the technique can be applied to a brake assembly, including the suspension system, mounted on a brake dynamometer. This ensures correct thermal and mechanical loading. Starting in the late 1980s, an increased number of researchers such as Eriksson et al. [9] and Massi et al., [10] have refocused interest in the role played by tribology in squeal generation. Friction and wear plays an important role, although it is not clear 
how to incorporate them into predictive models for disc brake squeal. Experimental techniques however are expensive and time consuming. Remedies found are very often efficient for that specific system only (Di Lisio et al. [11]), so may not be applicable to another one assembly, which looks apparently very similar.

Numerical methods have become very powerful, in terms of ability to incorporate much more accurate brake component models, including complex geometries, component interactions - friction and contact formulations, so their application in brake NVH (Noise Vibration and Harshness) studies is becoming much more prominent. Interface pressure distribution between the pad and the disc rotor is highly non uniform and significantly affected by different parameters (Tirovic and Day [12]). The dynamic friction normally depends on the local pressure, so the effect of the centre of pressure between the pad and the disc and its relation to reaction points at the caliper mounting and the pad/backplate abutment should be investigated very carefully (Fieldhouse $e t$ al. [13]). The publications of the influence of temperature on brake squeal are quite limited (AbuBakar et al. [14]), but this aspect represents an important topic. It can influence tangential in-plane modes of vibrations, Young's modulus change, material and shims shear modulus, and some geometrical effects such as the hat torsional stiffness, Ishii-Dodson et al. [15]. The commonly called 'rotating-heat-source' effect can be taken into account with the introduction of a fully coupled thermo-mechanical analysis before executing an instability study as demonstrated by Hassan et al. [16], [17], [18] and using complex eigenvalue technique by Kung et al. [19]. The FE method allows an accurate representation of complex geometries and boundary/loading conditions, which traditional lumped parameter techniques cannot address. Magnier et al. [20] successfully studied the influence of pad/disc contact on brake squeal. Brunel and Dufrénoy [21] conducted transient analyses of disc brake squealing modes. A very good overview of the numerical analysis of automotive disc brake squeal is presented by Chen et al. [22], Ouyang et al. [23], [24] and Chen [25]. More recently, Kim and Zhou [26], Esgandari and Olatunbosun [27] [28] and Tisson et al. [29] demonstrated the possibilities in improving squeal prediction and reducing its occurrence.

The above literature presents only a small selection of most relevant publications related to the problem studied, using theoretical, experimental and numerical techniques. The approaches shown have considerably advanced the understanding of brake squeal phenomenon but inevitably, the limitations of all approaches and techniques are still considerable. The general consensus among the scientific community on the fundamental cause of brake squeal is that it is generated by brake system dynamic instability. The squeal mechanisms can be divided in the following main categories:

a. Negative friction-velocity slope (friction force induced vibration);

b. 'Sprag-slip' or 'Stick-slip' (geometrically induced instabilities that do not require variations in the coefficient of friction);

c. 'Modal Coupling' or 'Binary Flutter' (two modes of vibration which are very close together in terms of resonant frequency, but are out of phase by $90^{\circ}$. Transfer of energy between the 2 modes leads to squeal). 


\section{The Methodology Developed}

Analytical approaches can only be applied to simplified models and geometries. Though they can be useful in pointing out to some mechanisms and phenomenon related to the squeal generation, brake assemblies geometries are far too complex for the analytical techniques to be used as an effective design tool.

Experimental approach can be only applied to an existing brake assembly. Consequently, the number and extent of changes or modifications to component geometry and material characteristics is very limited and such an approach often result in doing so called 'fixes', i.e. crude modifications and additions of mass or extra damping to resolve the problem, without addressing its very core/source. Furthermore, the knowledge gained is of limited use in generating new brake designs which are more resilient to squeal.

Numerical methods and computer technology are becoming more powerful, with commercially available software packages being continuously refined with improved modelling features enabling complex analyses of various aspects of brake assemblies - from braking performance to vibro-acoustic analysis. The problems in obtaining accurate results are often not related to the modelling capabilities of the specific computer hardware and software but to the ability in defining accurate material properties, as well as initial, boundary and interface conditions. The authors have conducted substantial research into improving modelling approaches, by carefully examining every step of the Finite Element (FE) modelling process and comparing the outputs with experimentally obtained results.

As a result of this effort, this paper presents an improved methodology for brake squeal propensity prediction at design stage. True geometry, material characteristics and thermal effects have been taken into account to reduce the discrepancy between the FE predictions and the experimental results. Four clearly defined "Stages" in conducting FE Squeal Analyses have been established, describing crucial input data, modelling procedures, output and validating results. The establishment and content of each of the Stages, and their relationships, will become clearer as they are presented in greater detail. It is worth pointing out here that the guidelines established are not only a research approach but a practical engineering tool, designed to be used in an industrial environment to generate new disc brake assemblies with improved NVH characteristics. The four main stages established are detailed below, with a schematic flowchart explaining the fundamentals shown in Figure 1:

- Stage 1: Free-free modal analysis of individual components. Natural frequencies and modes extracted with FE frequencies analyses have been correlated with the results from experimental modal analyses (EMA). Material characteristics, sensitivity analyses and advanced experimental techniques are applied from this early Stage.

- Stage 2: Creation of the full FE brake assembly model. FE static analyses were run to ensure that the assembly was mechanically loaded in the correct way. Again, in addition to inclusion of all important modelling aspects, advanced experimental techniques were employed in validation process.

- Stage 3: Transient, fully coupled thermo-mechanical analysis provides thermal deformation of the disc and contact pressure variations during the brake application, leading to a more representative FE model in 
which important information on temperature, associated change of material properties and disc coning are all taken into account.

- Stage 4: The stability analysis uses thermal results at specific times during braking, enabling the inclusion of thermal effects within the complex eigenvalue analysis. The unstable modes of the hot brake assembly have been finally analysed, with the positive real parts showing the instabilities, and the imaginary ones, the frequencies of vibrations. FE results were compared with dynamometer measurements, validating the entire process.

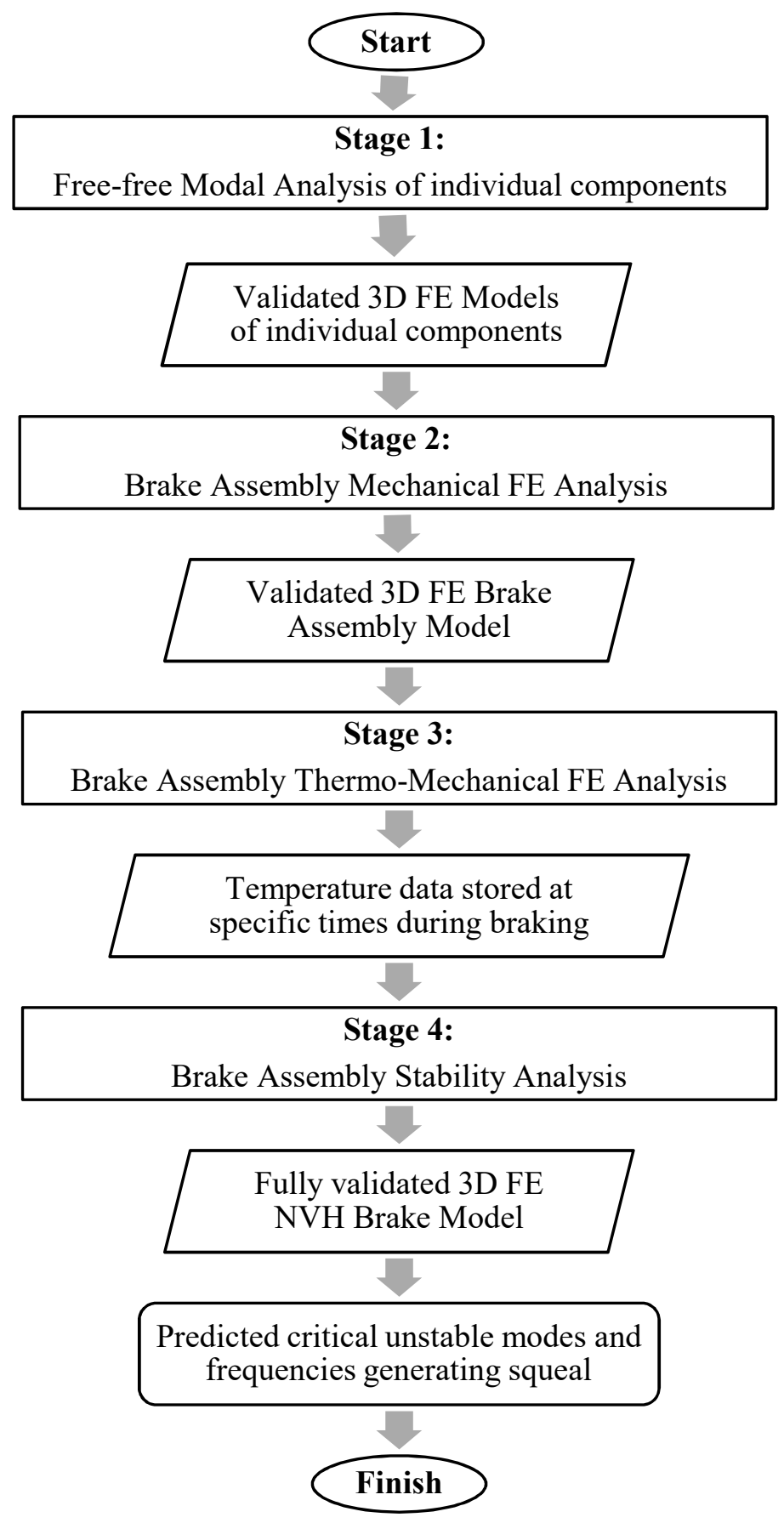

Figure 1: The Four Stages in the Analysis of Brake Squeal Propensity 


\section{Disc Brake Assembly Analysed}

The brake analysed is a front disc brake for a large, high performance Sport Utility Vehicle (SUV). The CAD model of the entire vehicle corner, including suspension and steering systems is shown in Figure 2a. Figure $2 \mathrm{~b}$ shows the actual assembly, as mounted on the brake dynamometer head in Cranfield University.

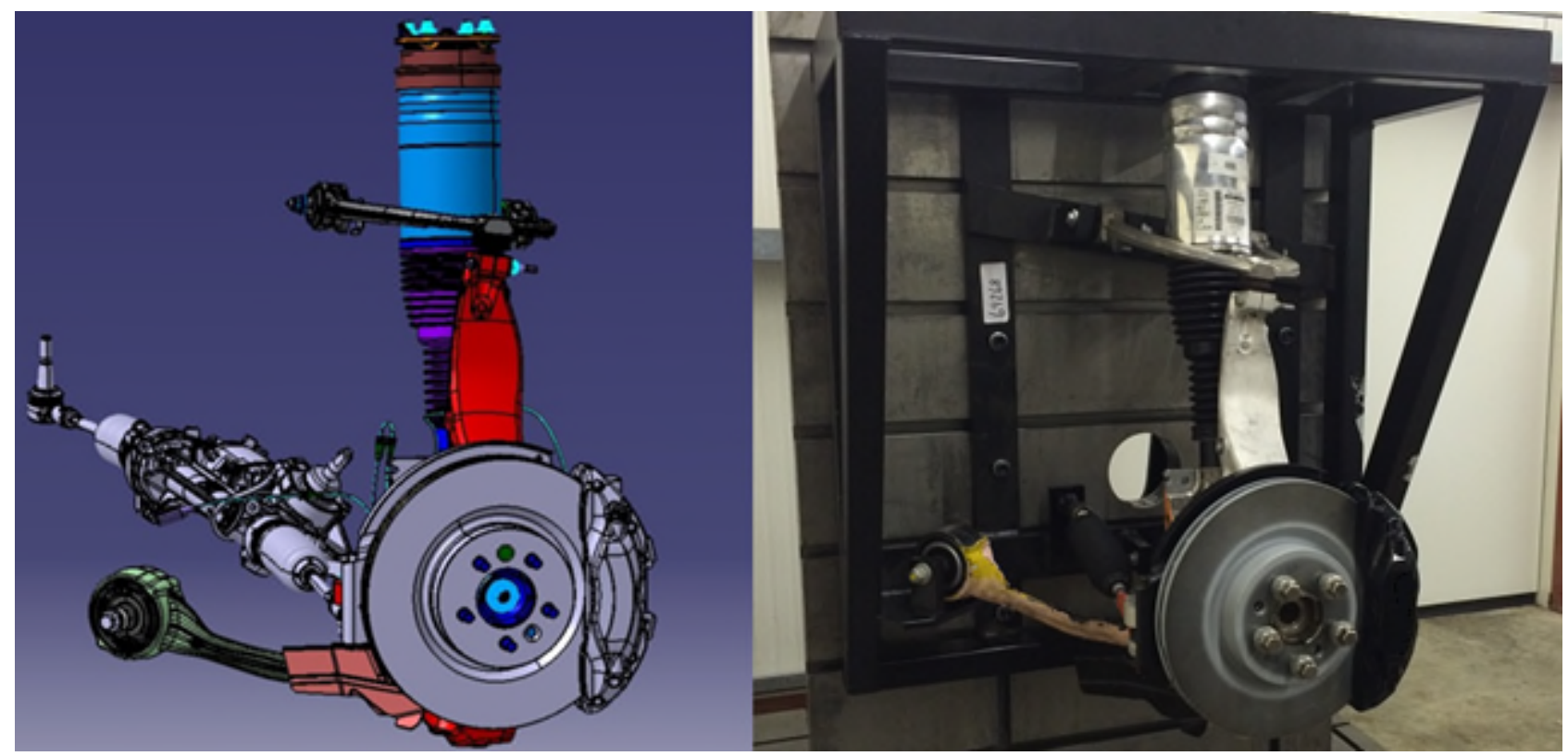

a)

b)

Figure 2: Vehicle corner with analysed brake assembly: a) CAD model; b) Brake dynamometer installation

Basic characteristics of major individual brake components are presented in Table 1. More details will follow, but it is worth pointing out that the disc is made of grey cast iron, the pads friction material is organic, with steel backplates, and the caliper is made from an aluminium alloy, having solid steel pistons.

\begin{tabular}{|c|c|c|c|c|c|}
\hline \multicolumn{2}{|l|}{ Disc } & \multicolumn{2}{|l|}{ Pads } & \multicolumn{2}{|l|}{ Caliper } \\
\hline Outer diameter (OD) & $360 \mathrm{~mm}$ & Nominal length & $130 \mathrm{~mm}$ & Type & 4 pot, fixed \\
\hline Inner diameter (ID) & $288 \mathrm{~mm}$ & Nominal width & $55 \mathrm{~mm}$ & Piston diameter & $46 \mathrm{~mm}$ \\
\hline $\begin{array}{c}\text { Total friction surface } \\
\text { thickness }\end{array}$ & $30 \mathrm{~mm}$ & $\begin{array}{c}\text { Friction material } \\
\text { thickness }\end{array}$ & $11 \mathrm{~mm}$ & $\begin{array}{c}\text { Distance between } \\
\text { piston axes }\end{array}$ & $60 \mathrm{~mm}$ \\
\hline Vane pattern & Pillared & $\begin{array}{l}\text { Backplate } \\
\text { thickness }\end{array}$ & $5.5 \mathrm{~mm}$ & Mounting holes distance & $150 \mathrm{~mm}$ \\
\hline Mass & $12.10 \mathrm{~kg}$ & Mass (each) & $0.645 \mathrm{~kg}$ & Mass (with pads) & $5.90 \mathrm{~kg}$ \\
\hline
\end{tabular}

Table 1: Basic characteristics of individual brake components

\section{Stage 1: Modal Analysis of Individual Brake Components}

It is often considered that with modern CAE (Computer Aided Engineering) approach, by using CAD (Computer Aided Design) models and associated material properties, then employing suitable FE analyses, natural modes and frequencies of individual parts will be predicted with high accuracy. Unfortunately, it has 
been proven - through authors' own work and experience, that that is not necessarily the case. Relatively small differences in parameters and/or other aspects of the analyses conducted, can lead to considerable, cumulative discrepancy between predicted (FE) and actual (measured) values of frequencies and modes. It is therefore necessary to pay utmost attention to every input value and every aspect of FE analyses. The outputs affected are not limited to natural frequencies and modes only but also to component strains and interface pressure distributions. It should be also pointed out that modelling also needs to be fast and cost-effective. All this will be analysed in detail for each major component of the brake assembly: the disc, pads and caliper.

The aim of a modal analysis is to determine natural frequencies and mode shapes of a brake assembly under dynamic excitation. It is widely used in industry and is essential in discovering the root causes of many noise, vibration and durability issues. From a mathematical point of view, the vibrational analysis of a structure with many degrees of freedom is a typical eigenvalue problem. The physical interpretation of the eigenvalues and eigenvectors, which come from solving the system, are that they represent respectively the frequencies and the corresponding mode shapes. Natural frequencies and corresponding mode shapes depend on geometry, distribution of mass and stiffness of the component analysed. Starting from the CAD model of the full brake assembly, major components were extracted and their individual models and mesh created. Natural frequencies and modes predicted using FE analyses were compared with corresponding experimental results (roving hammer method).

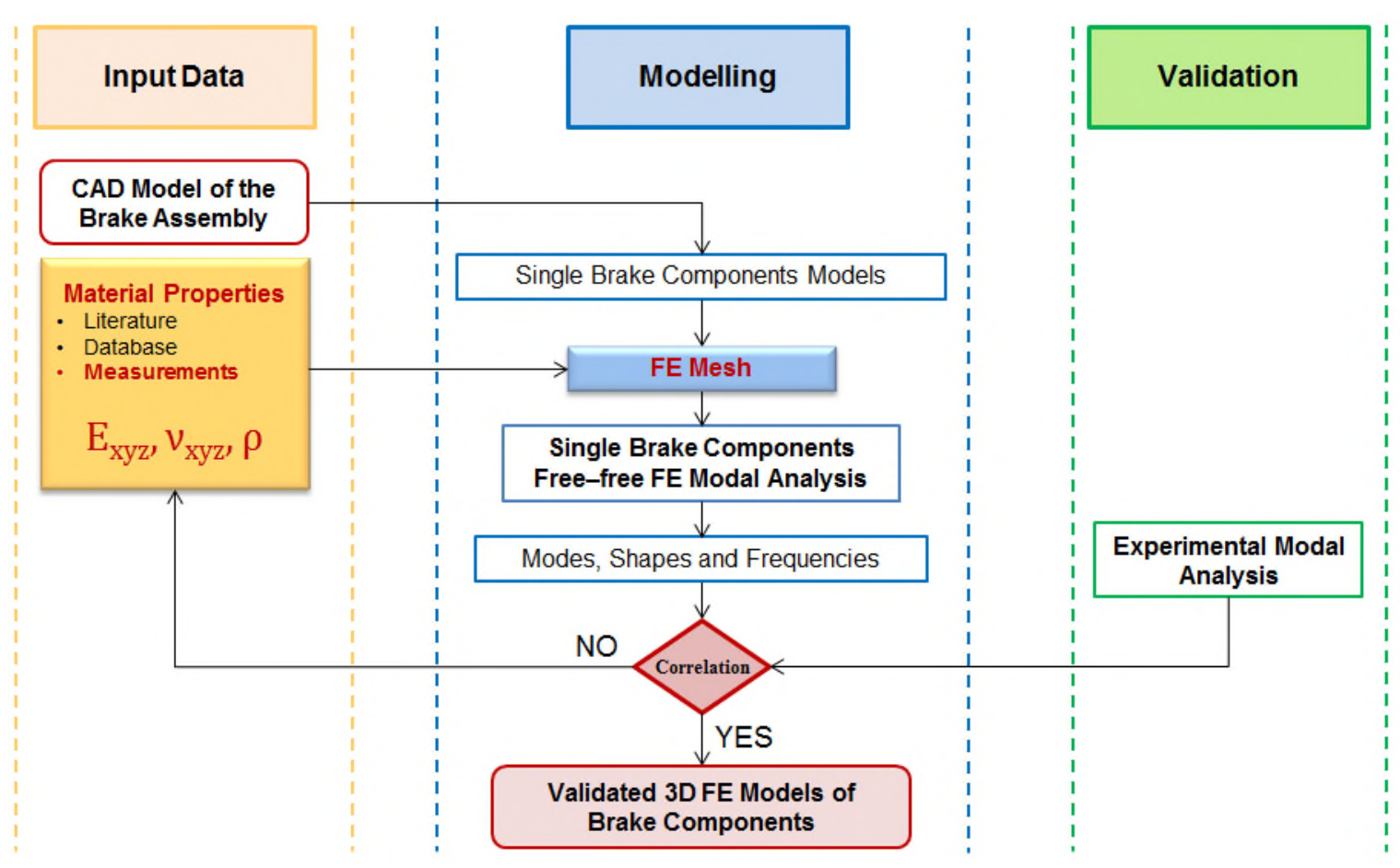

Figure 3: Stage 1 flowchart: FE Modal Analysis of individual brake components

An overview of the $1^{\text {st }}$ Stage is presented in Figure 3. As every other Stage, it contains three major streams: Input Data, Modelling and Validation. For Stage 1, as shown in Figure 3, Input Data are CAD Models and Material Properties. The ultimate outputs from Stage 1 are validated 3D FE Models of Individual Brake Components. 
Typically, the starting ('Input Data') point of the 'Modelling' (analysis) stream is the Brake Assembly CAD Model, which insures that all components fit together and also fit to the vehicle corner. Consequently, for FE modelling, these individual CAD models must be extracted from the brake CAD assembly. The process is not necessarily straightforward, as there might be various details that work well within CAD environment but cause problems with generating FE mesh. Material Properties ('Input Data') need to be also entered into the FE models, prior to conducting free-free FE modal analyses of individual components. Again, literature data might be extensive but of insufficient accuracy, therefore suitable internal databases and specific measurements need to be often conducted. Only after the FE models were carefully constructed, mashing optimised, and reliable material properties used, meaningful free-free FE modal analyses can be conducted. Modes, shapes and frequencies need then to be compared with Experimental Modal Analyses ('Validation') in order to gain confidence in the results obtained. In practice, to achieve good predictions, FE models and analyses may need to be modified and re-run, and material data may need to be updated through further measurements. This approach is to be conducted for each major brake component - the disc, pads and caliper, each having somewhat different specific characteristics and pitfalls.

\subsection{Disc modelling}

Several aspects proved to be particularly important in disc modelling, which required much attention in order to obtain reliable prediction of natural modes and frequencies. They included: Disc material (cast iron) characteristics, FE mesh/meshing type (free, mapped), FE element size and element type. Numerous analyses have been conducted and the influence of above characteristics on FE results investigated in detail. The results are compared to the experimental values (Experimental Modal Analyses - EMA). The experimental results were obtained by conducting own measurements, with some provided by the Universities of Liverpool and Bradford (roving hammer method). The disc was excited by means of a hammer from several points and different arrangements were selected. Both accelerometers and laser vibrometer were used. An example of tap test results, in the form of frequency response function (FRF), is presented in Figure 4.

Regarding the FE Disc model, in order to have the most efficient mesh, without excessively increasing the computational time, linear elements type C3D4 (4-node linear tetrahedron) were used in the first instance, varying the average element size. The analysis of the results indicates that the frequencies were strongly dependent on the element size adopted, so quadratic elements were finally used in case of free mesh, giving the confidence that the frequencies variation was independent from the element size adopted during the analysis. Considering that a free mesh using 10-node quadratic tetrahedrons (C3D10) is not the best solution regarding pressure distribution and contact problems, and with the aim of using brick elements (C3D8R) in the full 3D assembly model, the correlation between FE results and tap test was therefore checked again. To ensure the accuracy and reliability of CAE procedures, the density of the disc material (cast iron) and its Young's Modulus were measured. Material properties of production items might vary depending on the manufacturing process, so few tests were conducted at Bradford University, and an average value was finally considered. It may be argued that as long as material properties provide good correlation in terms of frequency and mode shape, the combination of properties used might not be that important. However, if an estimated 
value was applied to more complex simulations, including contact and thermal effects, the reliability of that particular result could then be in doubt. The same vibrational behaviour can be achieved with more than one combination, but the changes in contact at the pad/disc interface can lead to a different noise propensity. Table 2 summarised what has been discussed above, showing the benefits of using a mapped mesh and measured material properties. Note that 'Mode 1' is never used in Complex Eigenvalue Analysis. The 'first' mode which is possibly coupled and generates squeal is the $2^{\text {nd }}$ mode.

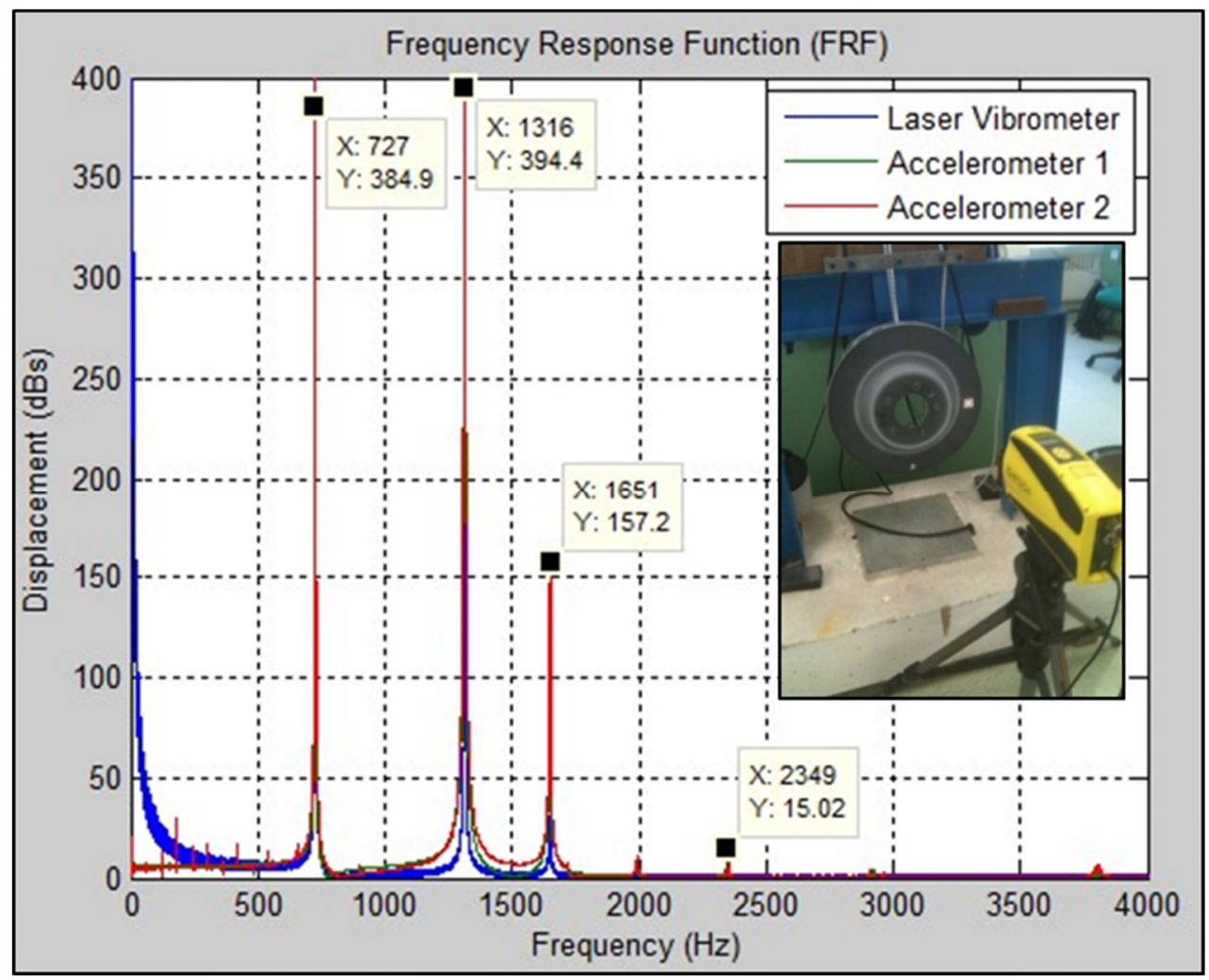

Figure 4: Combination of results from 'free-free' disc hammer test

The results presented in Table 2 clearly indicate the need to perform own measurements of disc material characteristics, as 'generic' values lead to the errors of the order of $5 \%$ in predicting natural frequencies. When the measurements of the actual disc material were conducted and these values used in predicting natural frequencies, the correlation with measured values was exceptionally good, with differences dropping below $1 \%$ (for $1^{\text {st }}$ order elements). Even if the difference in each material characteristic influencing the natural frequencies (Young's Modulus, Density and Poisson's Ratio) is not substantial, their cumulative effect can be pronounced, leading to inaccurate results. The influence of the three characteristics is complex and by varying inter-relations (i.e. reducing the value for one and increasing the value for the other characteristic) it is possible to artificially achieve natural frequencies similar to those measured. This 'tuning' approach is not only wrong but also dangerous, as the results obtained can be very misleading in later stages of the research, when more complex analyses are conducted. 


\begin{tabular}{|c|c|c|c|c|c|c|c|c|c|}
\hline \multirow{3}{*}{ Mode } & \multirow{3}{*}{$\begin{array}{c}\text { Experimental } \\
\text { (EMA) }\end{array}$} & \multicolumn{4}{|c|}{ Finite Element } & \multirow{2}{*}{\multicolumn{4}{|c|}{ \% Difference (EMA to FE) }} \\
\hline & & \multicolumn{2}{|c|}{$\begin{array}{l}\text { Element Type: } \\
4 \mathrm{~mm} 1^{\text {st }} \text { order }\end{array}$} & \multicolumn{2}{|c|}{$\begin{array}{l}\text { Element Type: } \\
4 \mathrm{~mm} 2^{\text {nd }} \text { order }\end{array}$} & & & & \\
\hline & & C3D8R* & C3D8R*: & C3D20R* & C3D20R** & $\mathrm{C} 3 \mathrm{D} 8 \mathrm{R} *$ & C3D8R** & C3D20R* $\mathrm{C}$ & C3D20R** \\
\hline 2 & 672 & 666 & 628 & 675 & 637 & $-0.9 \%$ & $-6.5 \%$ & $0.4 \%$ & $-5.2 \%$ \\
\hline 3 & 1562 & 1564 & 1476 & 1583 & 1491 & $0.1 \%$ & $-5.5 \%$ & $1.3 \%$ & $-4.5 \%$ \\
\hline 4 & 2606 & 2609 & 2462 & 2643 & 2493 & $0.1 \%$ & $-5.5 \%$ & $1.4 \%$ & $-4.3 \%$ \\
\hline 5 & 3717 & 3708 & 3498 & 3764 & 3551 & $-0.2 \%$ & $-5.9 \%$ & $1.3 \%$ & $-4.5 \%$ \\
\hline 6 & 4849 & 4825 & 4552 & 4910 & 4633 & $-0.5 \%$ & $-6.1 \%$ & $1.3 \%$ & $-4.5 \%$ \\
\hline 7 & 5986 & 5948 & 5612 & 6069 & 5726 & $-0.6 \%$ & $-6.2 \%$ & $1.4 \%$ & $-4.3 \%$ \\
\hline 8 & 7149 & 7074 & 6675 & 7240 & 6830 & $-1.0 \%$ & $-6.6 \%$ & $1.3 \%$ & $-4.5 \%$ \\
\hline 9 & 8326 & 8209 & 7745 & 8424 & 7948 & $-1.4 \%$ & $-7.0 \%$ & $1.2 \%$ & $-4.5 \%$ \\
\hline 10 & 9547 & 9358 & 8830 & 9630 & 9087 & $-2.0 \%$ & $-7.5 \%$ & $0.9 \%$ & $-4.8 \%$ \\
\hline \multirow{2}{*}{\multicolumn{6}{|c|}{ AVERAGE }} & \multicolumn{2}{|c|}{$1^{\text {st }}$ order Elements } & \multicolumn{2}{|c|}{$2^{\text {nd }}$ order Elements } \\
\hline & & & & & & $-0.7 \%$ & $-6.3 \%$ & $1.2 \%$ & $-4.6 \%$ \\
\hline
\end{tabular}

\begin{tabular}{|c|c|c|}
\hline \multirow{2}{*}{$\begin{array}{c}\text { Characteristics of disc material } \\
\text { Cast Iron GG150 }\end{array}$} & \multicolumn{2}{|c|}{ Colour Key: } \\
\cline { 2 - 3 } & *Measured & **'Generic' \\
\hline Young's Modulus & $\mathrm{E}=110.7 \mathrm{GPa}$ & $\mathrm{E}=100 \mathrm{GPa}$ \\
\hline Density & $\rho=6900 \mathrm{~kg} / \mathrm{m}^{3}$ & $\rho=7000 \mathrm{~kg} / \mathrm{m}^{3}$ \\
\hline Poisson's Ratio & $v=0.245$ & $v=0.23$ \\
\hline
\end{tabular}

Table 2: Comparison between experimental and $\mathrm{FE}$ natural frequencies (in $\mathrm{Hz}$ ) and modes of the disc

Table 2 also demonstrates that linear $\left(1^{\text {st }}\right.$ order $)$ reduced integration elements in case of mapped mesh can give accurate results, contrary to what was happening using the free mesh. In addition to higher accuracy, the models using $1^{\text {st }}$ order elements also run much faster, reducing CPU time and costs, and increasing efficiency of the development process.

\subsection{Pad modelling}

Friction pads are having by far the simplest geometry of all major brake components but their characteristics are most difficult to predict. Organic friction material represents largest proportion of the pad. Having nonlinear, non-isotropic, viscoelastic properties which considerably change with temperature, experiencing reversible and non-reversible changes and exposed to almost complete wear, the friction material is most difficult to accurately model.

Similarly to disc modelling, selection of suitable element size and type when meshing pads, plays an important role in obtaining reliable results. Furthermore, pad mesh must enable accurate introduction of contacts with pistons, calipers and disc, with thermal loads and wear setting even more stringent requirements. Modelling of the backplate, made of mild steel, is relatively straightforward, however modelling of the vibration absorbing shims attached to the pad backplate is very challenging. In this work, most tests and modelling were performed without the shims, since its damping effect was neglected during the FE simulations conducted. 


\subsubsection{Friction Material Measurements}

Initial modelling results showed obvious limitations, requiring much more detailed measurements of pad properties. Pad compressibility tests were performed in accordance with SAE-J2468 but such experiments are more useful in validating FE models in static tests and estimating brake pedal travel, when pad is exposed to actuation forces, rather than establishing friction material properties required for complex FE analyses. A detailed study of friction material properties at room temperature has therefore been conducted. Samples were cut from actual pads, carefully cut and polished, taking care of their position on the pad and orientation. Compressive tests were then conducted, by loading samples in all 3 directions. The tests were performed on Instron 5965 test equipment (compression/tension type, providing maximum force of $5 \mathrm{kN}$ ). In order to determine friction material characteristics 9 samples (blocks) were used, cut from each pad, and 4 types of tests were conducted:

a) Loading non-instrumented samples in 3 directions in the compression machine and measuring displacements (accounting for deflection/extension of the test machine);

b) The same tests (a) were conducted on samples which had strain gauges installed;

c) Tests (a) were conducted on samples with installed optical fibre sensors for measuring strains;

d) Tests (a) were conducted on samples which were specially prepared (painted) and Digital Image Correlation (DIC) equipment was used to measure displacements and strains.

It would take too much space to show all the results, hence only some measurements will be presented, together with major relationships, comments and conclusions.

Figure 5 shows the set-up with the use of Digital Image Correlation (DIC) equipment. DIC is a non-contact method for measuring the whole field displacement. It is based on the principle of perspective view, a photogrammetric principle (similar to human vision). Introduced by researchers at the University of South Carolina in the early 1980s, it has been optimized and improved in recent years. It processes several object images to calculate the deformation at any point in the field, using correlation algorithms. The strains can be finally calculated directly by the differentiation of the displacements measured.

The Digital 3D Image Correlation System used is the Q-400 by Dantec Dynamics and more details on experimental procedure and software can be found on the Company website (www.dantecdynamics.com). As expected, due to the shape of the samples, especially in the first two cases (blocks 2 and 5), a buckling effect was observed, as shown in Figure 6. That information was used in order to minimise that unwanted side effect. A line element on the object surface was defined by two points. The graph shows the displacement in $\mathrm{z}$ direction along that specific line. Another advantage of $\mathrm{D}$ technique, compared to the traditional strain gauges, is the possibility to separate the actual deformation of the sample tested from the rigid body motion (RBMR function). The dedicated software (INSTRA-4D) has also powerful tools which allow a very detailed postprocessing of the results obtained. 
Page 13 of 41

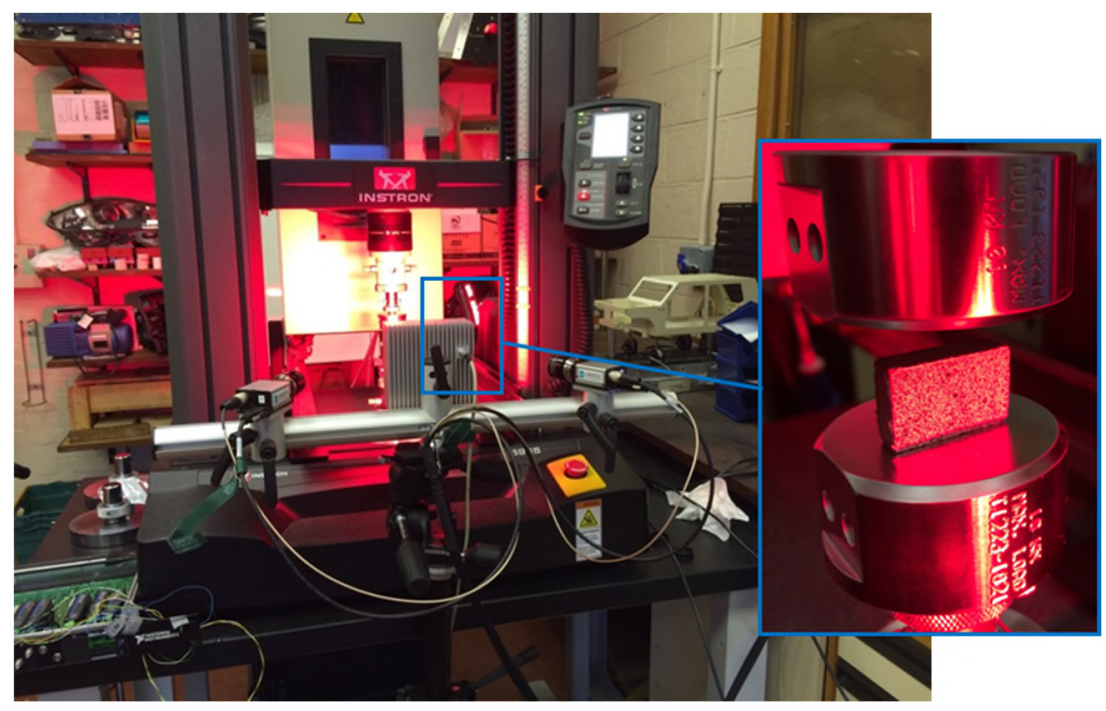

Figure 5: Experimental set-up and DIC strain measurements

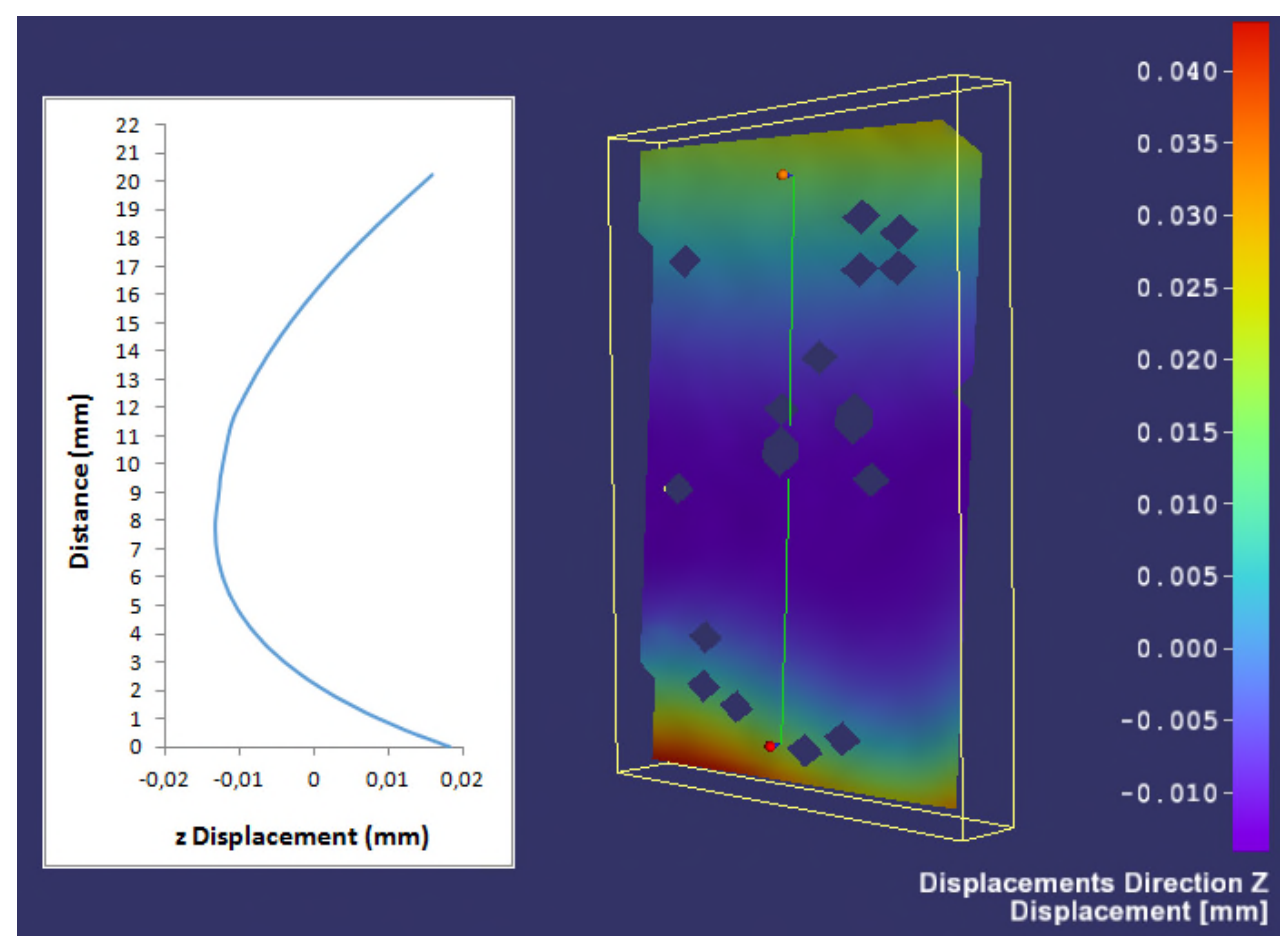

Figure 6: Displacement in z direction ("Buckling effect") for block 2

The local influence of the different friction material constituents and fibres orientation can be observed, but it is also possible to have an average of the strains over the entire surface, owing to the filters available (local regression and smoothing spline). The overall procedure is divided in steps which are actually snapshots of the deformed object during the loading and unloading cycle. Displacement and strain data are displayed relative to a reference step, which can be the initial one used to correlate the images between the cameras (reference step), or any other intermediate one. The line drawn on the surface is basically a virtual extensometer allowing the estimation of tangential and principal strains and related standard deviations. 


\section{Page 14 of 41}

By using these post-processing tools is possible to measure strains in orthogonal directions and extract the Poisson's ratio of the friction material and update the material properties to be used in the FE analyses. Figure 7 shows the results for Blocks 2 and 5, presenting strain changes during the loading-unloading cycle and calculated Poisson's ratio.
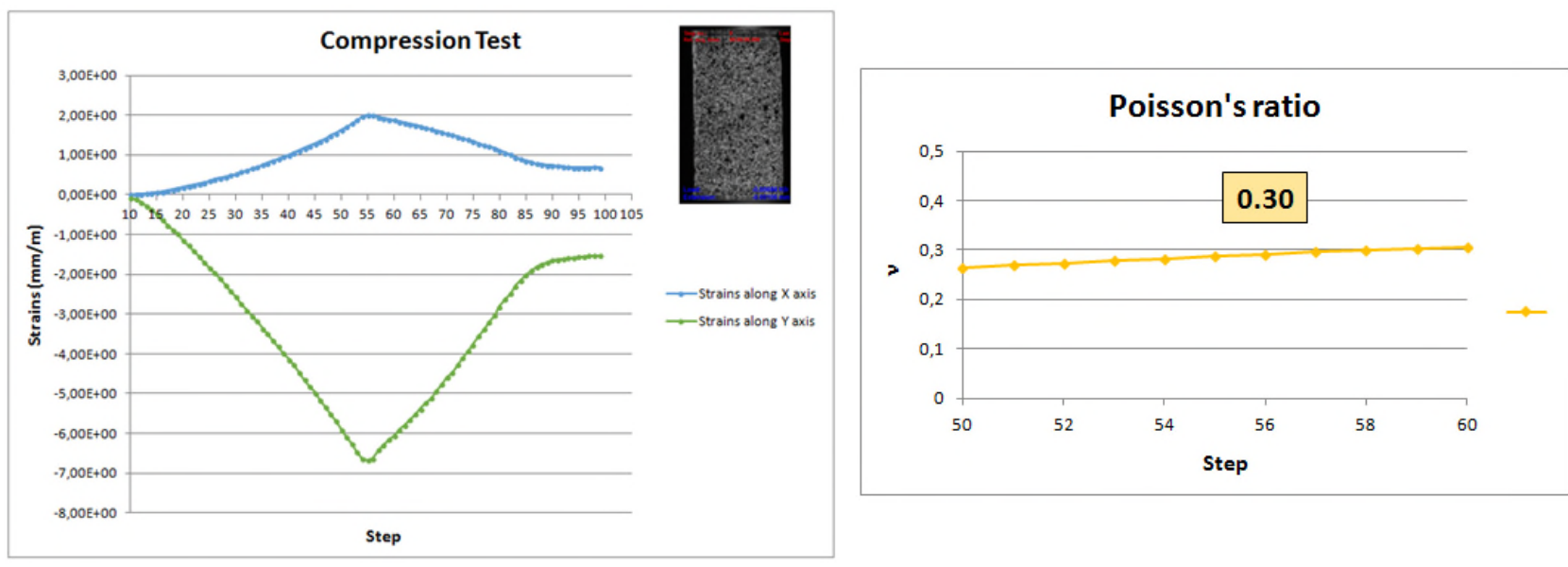

a)
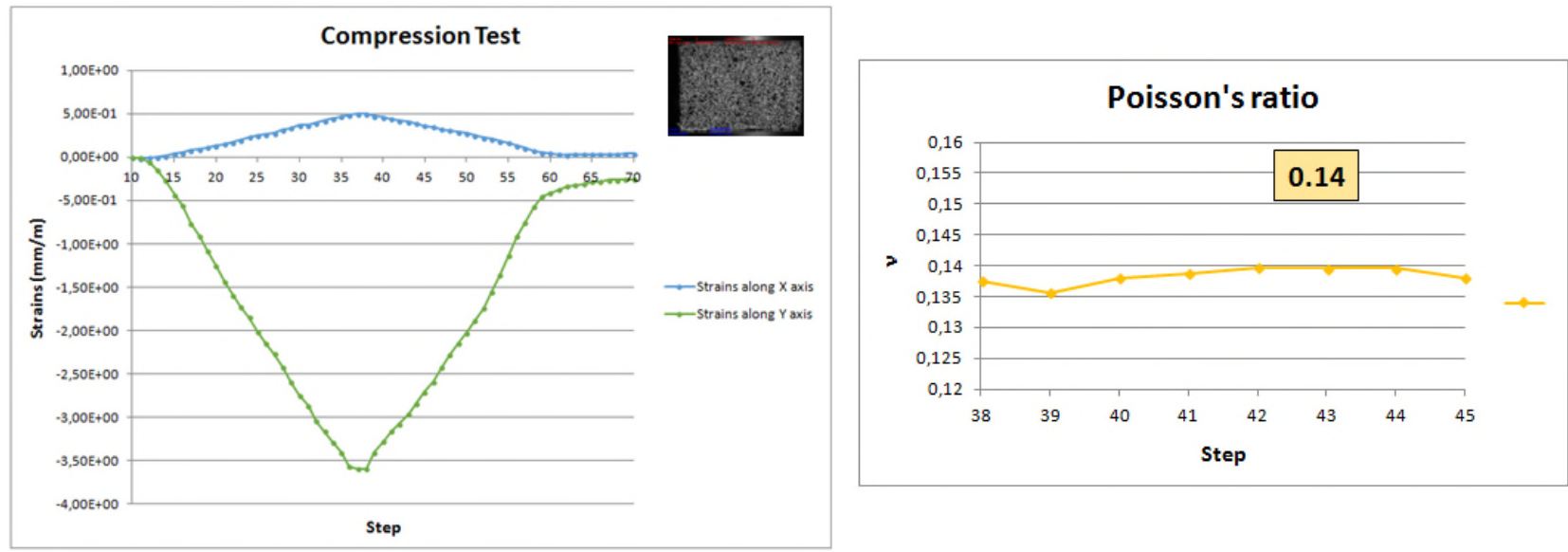

b)

Figure 7: Processed DIC strain measurements: a) Block 2; b) Block 5

\subsubsection{Friction Material Modelling}

The friction material shows profoundly anisotropic characteristics, having one engineering property in the inplane direction of the pad surface and a different property in the out-of-plane direction. The elastic matrix $\mathbf{C}$ can be defined as follows:

$$
\boldsymbol{\sigma}=\mathbf{C} \varepsilon \quad \text { where } \quad \mathbf{C}=\left[\begin{array}{cccccc}
C_{11} & C_{12} & C_{13} & 0 & 0 & 0 \\
C_{21} & C_{22} & C_{23} & 0 & 0 & 0 \\
C_{31} & C_{32} & C_{33} & 0 & 0 & 0 \\
0 & 0 & 0 & C_{44} & 0 & 0 \\
0 & 0 & 0 & 0 & C_{55} & 0 \\
0 & 0 & 0 & 0 & 0 & C_{55}
\end{array}\right]
$$


The subscript 1 and 2 represent pad in-plane tangential and radial directions, respectively, and the subscript 3 represents pad out of plane direction. Only five of the engineering constants are independent, since $\mathrm{C}_{44}=\left(\mathrm{C}_{11}\right.$ $-\mathrm{C}_{12}$ ) / 2. ABAQUS anisotropic data (Cij) can be directly calculated from the measured engineering constants. Once a local coordinate system has been defined and assigned to the pad friction material, the material anisotropy is successfully described introducing the values of the elastic matrix in the material deck.

\subsubsection{Pad natural modes and frequencies}

In order to reproduce the experimental set-up all constraints were removed (free-free modal analysis). During the solution stage, an eigenvalue technique is used to extract the natural frequencies of the system. There are two options available in ABAQUS for extraction of natural frequencies: subspace and Lanczos method. For a large number of Eigen modes, the Lanczos method works faster than the subspace method. Since the analysis contains many degrees of freedom the latter Eigen solver was adopted. Only the range between $1 \mathrm{kHz}$ and 10 $\mathrm{kHz}$, typical of brake squeal, was considered. Figure 8 shows the results obtained and Table 3 highlights the difference with the experimental tap tests.

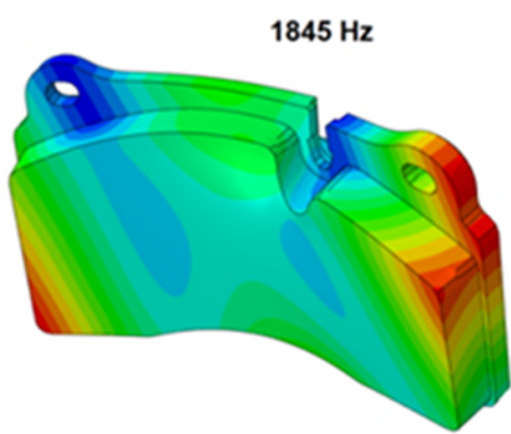

$1^{\text {st }}$ bending mode

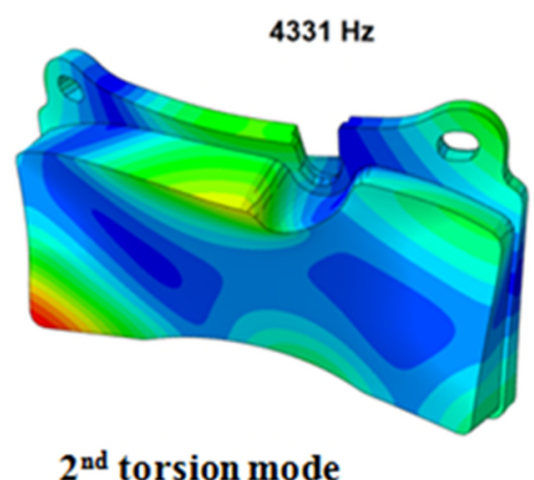

$2091 \mathrm{~Hz}$

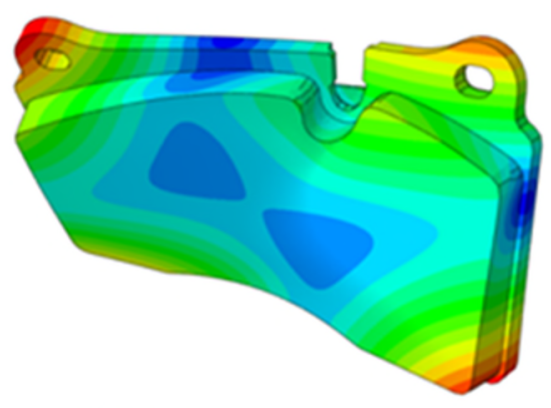

$1^{\text {st }}$ torsion mode

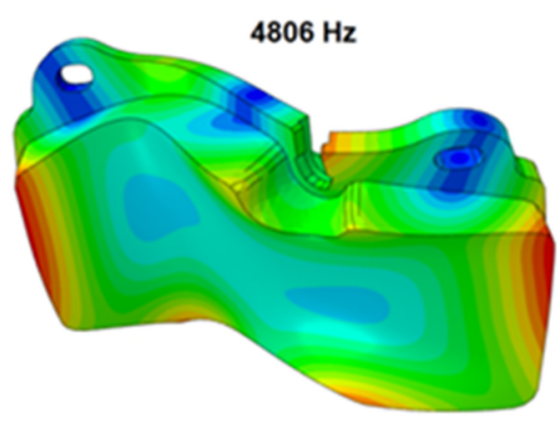

$2^{\text {nd }}$ bending mode

Figure 8: FE predicted natural frequencies and modes for the pads

Regarding the meshing procedure, the same type of elements used for the disc (C3D8R) was adopted, with an average size of $4 \mathrm{~mm}$. Further details will be given when explaining Stage 2 - Brake Assembly Modelling (Section 5). In this case, even more complex requirements are imposed on pad mesh, to ensure compatibility 
and high accuracy of contact definitions between the pad and disc, pad and caliper abutments, as well as pad and hydraulic pistons.

\begin{tabular}{|c|c|c|c|c|}
\hline Mode & Description & Experimental & FE Hex 4mm & $\Delta(\mathbf{\%})$ \\
\hline 1 & $1^{\text {st }}$ Bending & $1846 \mathrm{~Hz}$ & $1846 \mathrm{~Hz}$ & $0.0 \%$ \\
\hline 2 & $1^{\text {st }}$ Torsion & $2082 \mathrm{~Hz}$ & $2098 \mathrm{~Hz}$ & $0.8 \%$ \\
\hline 3 & $2^{\text {nd }}$ Torsion & $4575 \mathrm{~Hz}$ & $4340 \mathrm{~Hz}$ & $-5.1 \%$ \\
\hline 4 & $2^{\text {nd }}$ Bending & $4761 \mathrm{~Hz}$ & $4791 \mathrm{~Hz}$ & $0.6 \%$ \\
\hline
\end{tabular}

Table 3: FE and experimental natural frequencies comparison

\subsection{Caliper Modelling}

Geometrically, the caliper is most complex component of the brake assembly. It is not only difficult to model complex geometry, but also interaction with other parts - pistons and pads. As shown in Figure 9, the caliper is of a fixed type, with 4 opposed pistons, 2 per side. The caliper consists of 2 forged aluminium alloy halves, machined and bolted together. Caliper CAD models and FE mesh are all shown in Figure 9, with red circles indicating the machined regions where additional steel masses can be bolted to shift natural frequencies and modes of the caliper, which will be discussed later.

The type of meshing technique adopted (free mesh using tetrahedrons) is a consequence of the complex shape of the caliper itself. An excessive simplification of the geometry will entail a completely different vibrational behaviour. Even small details, such as chamfers and fillets, were necessary to keep, making pretty much impossible mapped meshing with brick elements, except for the pad/caliper abutments.
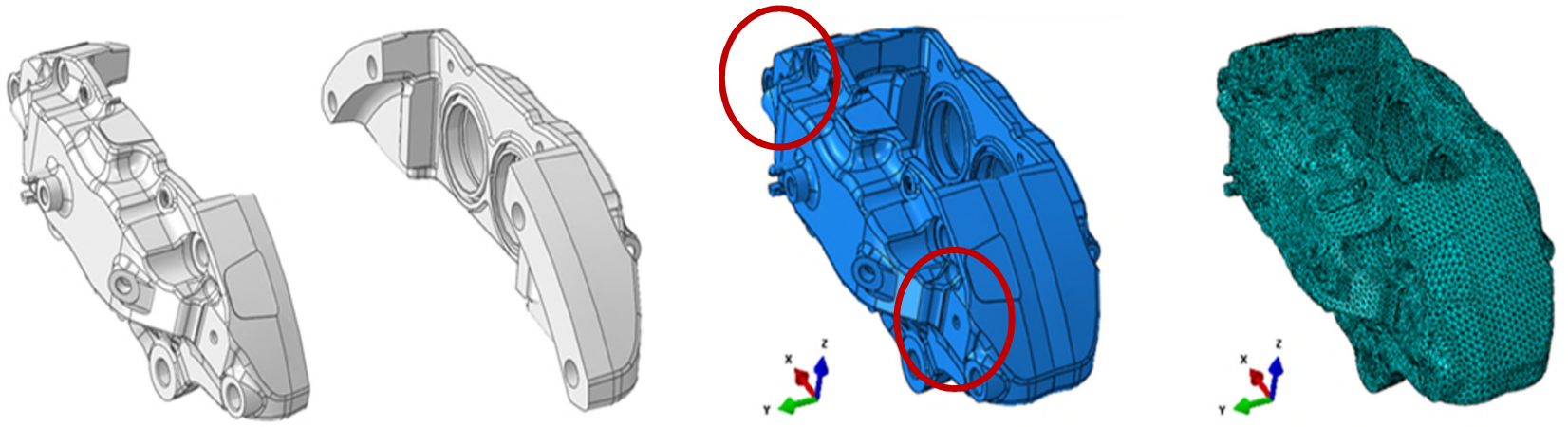

a)

b)

c)

Figure 9: Brake Caliper: a) and b) CAD models; c) FE mesh 


\subsubsection{Caliper without steel blocks (as shown in Figure 9)}

Similarly to the other two brake components, a detail investigation of types of elements used was conducted for the caliper. This included linear $\left(1^{\text {st }}\right.$ order $)$ and quadratic $\left(2^{\text {nd }}\right.$ order $)$ elements of various sizes. Once again linear elements didn't show good convergence, with predicted natural frequencies higher than measured, up to a maximum of $120 \mathrm{~Hz}$. The use of quadratic elements was also investigated, with results summarised in Figure 10 and Table 4 . The predicted values are lower for the first, fifth and sixth mode, but higher for modes two, three and four. The difference in frequencies can be related to the lack of information on the material properties of aluminium alloy used, but the modes predicted are exactly the same as the ones measured experimentally.

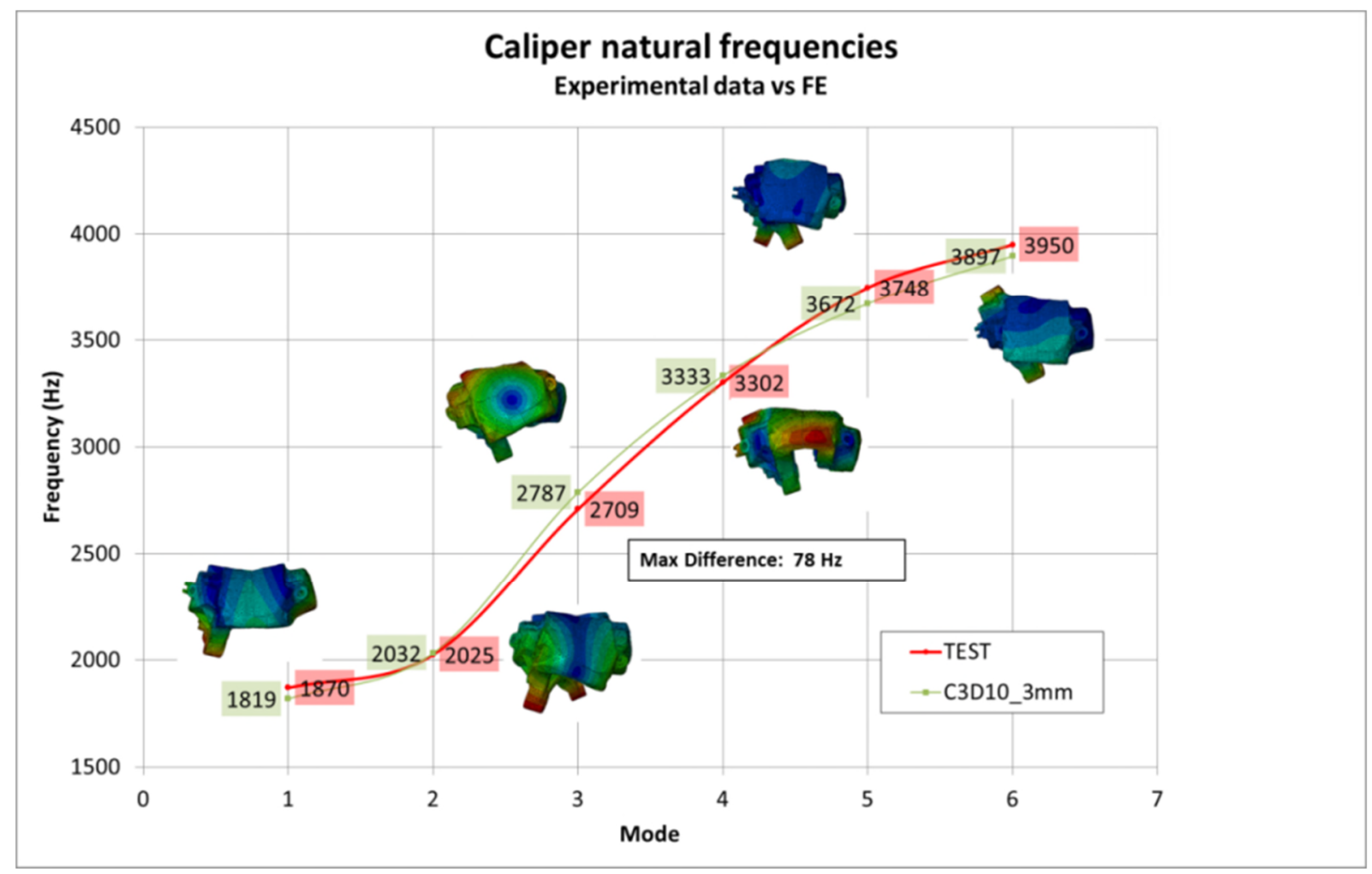

Figure 10: Caliper mode shape and natural frequencies using quadratic elements

\begin{tabular}{|c|c|c|c|c|c|c|c|}
\hline Element Type C3D10 & \multicolumn{7}{|c|}{ Mode (Hz) } \\
\hline Mesh size (mm) & $\mathbf{1}$ & $\mathbf{2}$ & $\mathbf{3}$ & $\mathbf{4}$ & $\mathbf{5}$ & $\mathbf{6}$ & $\Delta \mathbf{m a x}$ \\
\hline $2 \mathrm{~mm}$ & 1819 & 2031 & 2785 & 3332 & 3670 & 3895 & $2.81 \%$ \\
\hline $3 \mathrm{~mm}$ & 1819 & 2032 & 2787 & 3333 & 3672 & 3897 & $2.88 \%$ \\
\hline $4 \mathrm{~mm}$ & 1820 & 2033 & 2788 & 3334 & 3674 & 3899 & $2.92 \%$ \\
\hline Experimental & $\mathbf{1 8 7 0}$ & $\mathbf{2 0 2 5}$ & $\mathbf{2 7 0 9}$ & $\mathbf{3 3 0 2}$ & $\mathbf{3 7 4 8}$ & $\mathbf{3 9 5 0}$ & - \\
\hline
\end{tabular}

Table 4: First six caliper natural frequencies and modes (quadratic elements)

\subsubsection{Caliper with steel blocks (as shown in Figure 11)}

As already mentioned, two steel blocks measuring $25 \times 30 \times 55 \mathrm{~mm}$, having a mass of $0.3 \mathrm{~kg}$ each, were fastened (bolted) onto the caliper, as shown in Figure 11. The only purpose of adding blocks (an undesirable unsprung 
mass) was to shift natural modes and frequencies. The specific locations were chosen (see Figures 9 and 11) to decouple disc and caliper response around the target frequency of $2.7 \mathrm{kHz}$, considering functionality and packaging constraints.

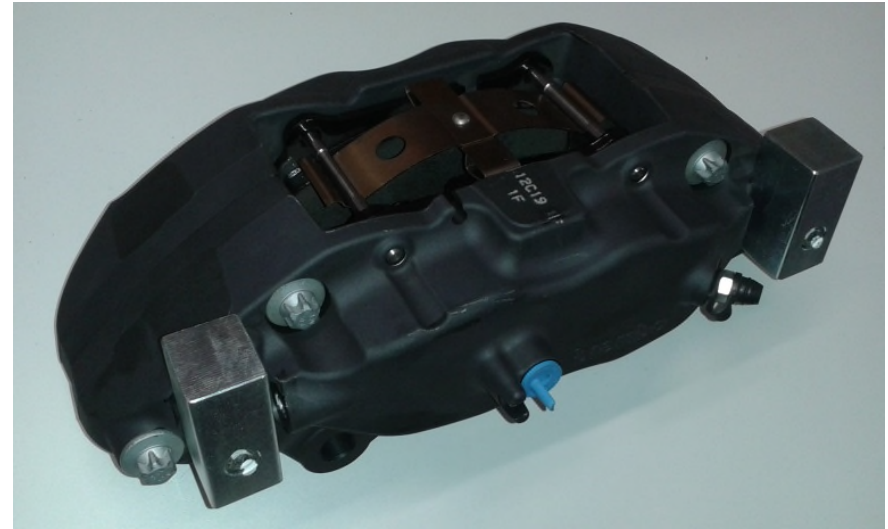

a)

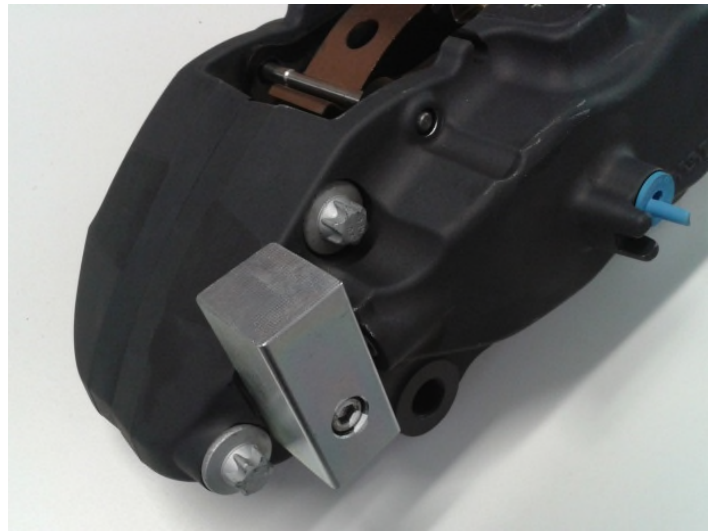

b)

Figure 11: Brake caliper with blocks: a) global view; b) block detail

FE modelling was performed using linear and quadratic elements. The latter were finally adopted as more accurate (see also the results for caliper without blocks, Figure 9 and Table 4). The FE results obtained and comparisons with (experimental) tap tests are given in Figure 12 and Table 5.

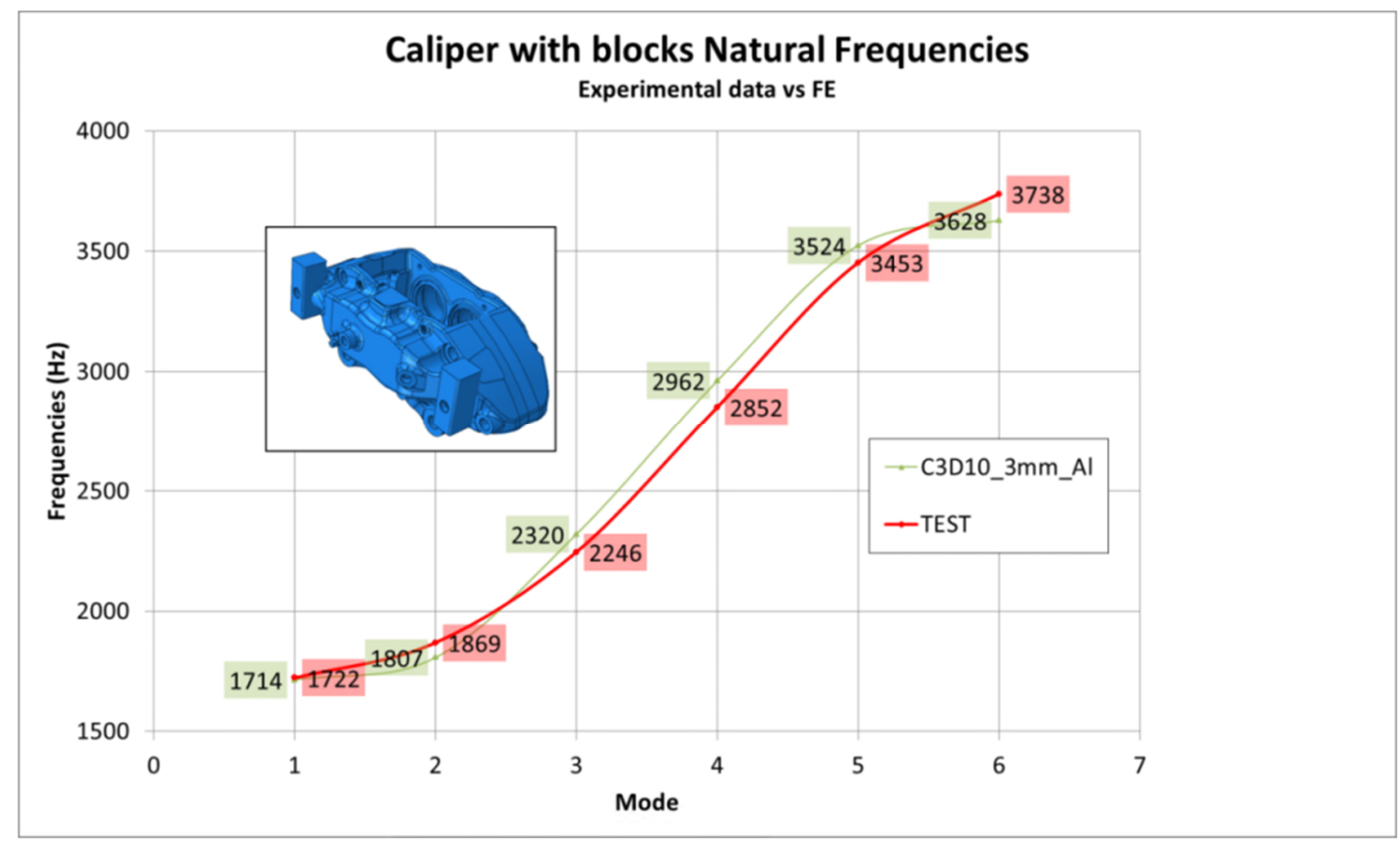

Figure 12: Caliper with blocks: Modes and natural frequencies using quadratic elements 
Page 19 of 41

\begin{tabular}{|c|c|c|c|c|c|c|c|}
\hline \multirow{2}{*}{ Element Type C3D10 } & \multicolumn{5}{|c|}{ Mode / Frequency(Hz) } & $\Delta$ max \\
\cline { 2 - 8 } & $\mathbf{1}$ & $\mathbf{2}$ & $\mathbf{3}$ & $\mathbf{4}$ & $\mathbf{5}$ & $\mathbf{6}$ & $\mathbf{\%}$ \\
\hline FE Mesh size 3 mm & 1714 & 1807 & 2320 & 2962 & 3524 & 3628 & 3.29 \\
\hline Experimental & 1722 & 1869 & 2246 & 2852 & 3453 & 3738 & - \\
\hline
\end{tabular}

Table 5: Caliper with blocks: First six natural frequencies and modes (quadratic elements)

As can be observed, comparing the frequency of the caliper with and without block, a shift of $463 \mathrm{~Hz}$ was achieved for the mode 3. Experimental modal analysis of the caliper with blocks in free-free condition was also performed, as summarised in Figure 13 and Table 6.

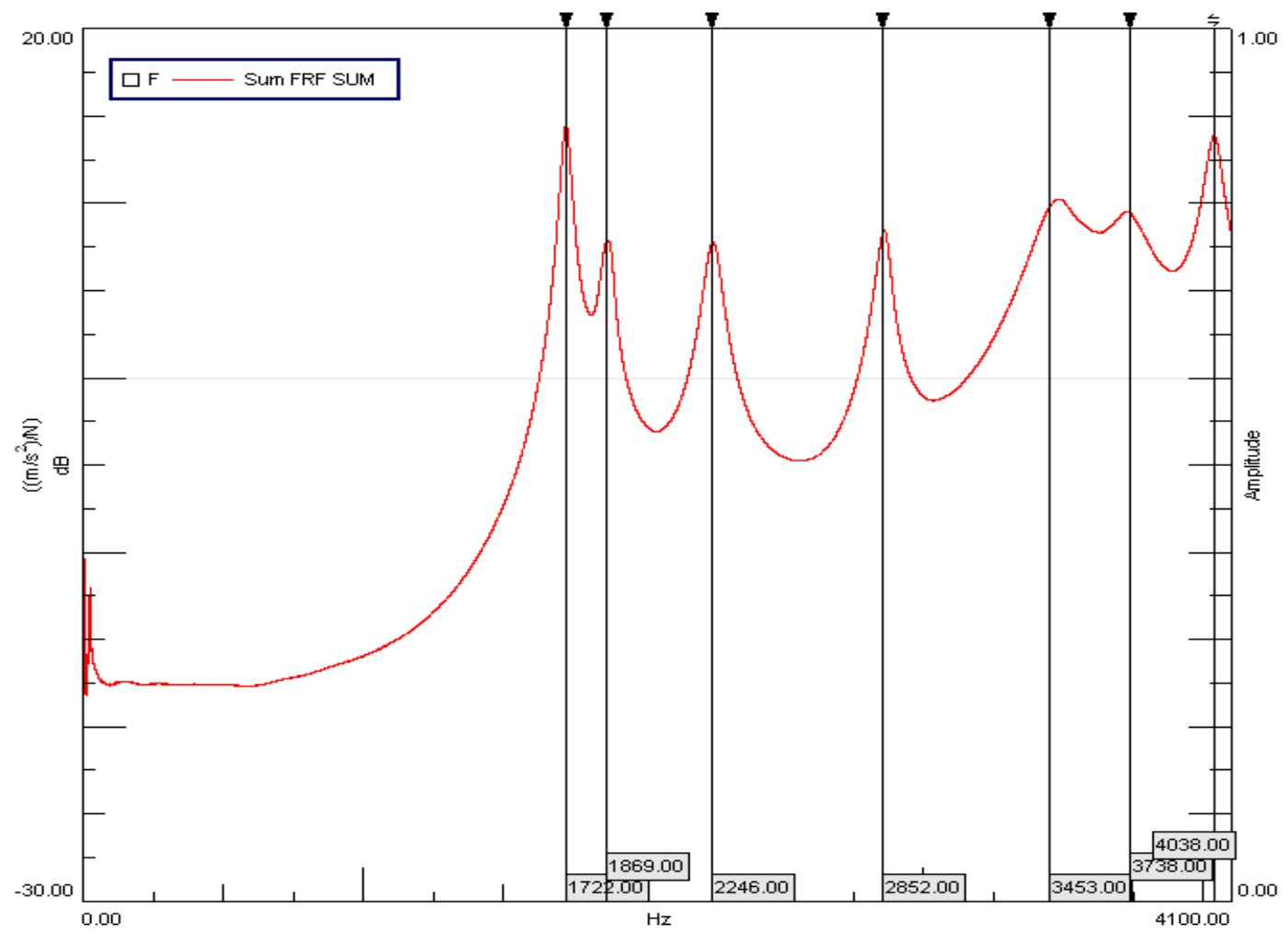

Figure 13: Experimental modal analysis results for the caliper with blocks

\begin{tabular}{|c|c|c|c|}
\hline Mode Number & Frequency $\mathbf{( H z )}$ & Damping (\%) & Description \\
\hline 1 & 1722 & 1.02 & Torsion \\
\hline 2 & 1869 & 0.94 & Panting across lower surface \\
\hline 3 & 2246 & 1.51 & Top edges front-back lateral out of phase \\
\hline 4 & 2852 & 1.14 & Bending \\
\hline 5 & 3453 & 2.88 & Masses fore-aft out of phase \\
\hline 6 & 3738 & 2.07 & Twist of fixing points \\
\hline
\end{tabular}

Table 6: Experimental modal analysis results for the caliper with blocks 


\section{Stage 2: Brake Assembly Mechanical FE Analysis}

The flowchart describing the activities in Stage 2 is show in Figure 14. It also contains three streams: 'Input Data', 'Modelling' and 'Validation'. Input Data is actually the output from Stage 1, containing validated 3D FE models of individual brake components. However, assembly modelling aspects require further validations, and material properties may need to be further investigating, adding to the Input Data stream.

The Modelling stream starts with generating the 3D assembly FE model. This procedure is not as simple as it might look, as there are still many modelling and meshing aspects which will only become prominent in the 'loaded assembly arrangement'. Initially, a precise positioning and clearing procedure is necessary to ensure correct physical positions and contact definitions. Then, FE static analyses can be conducted, introducing various preloads (clips, springs, bolts etc.) and hydraulic actuating pressure.

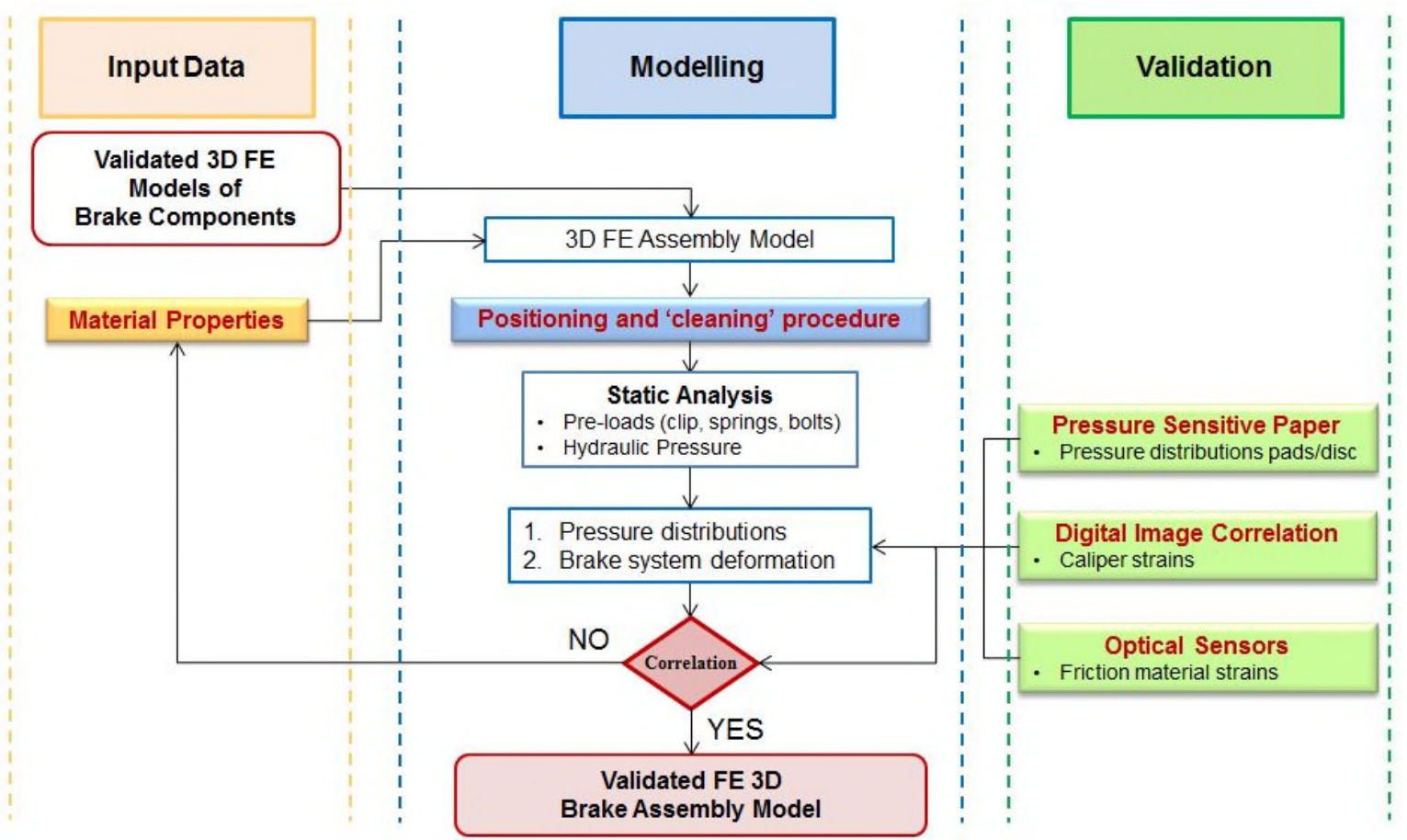

Figure 14: Stage 2 flowchart: Brake Assembly Mechanical Analysis

FE analyses can create multiple outputs but for the validation purposes, with interface pressure distributions and deformation of brake components as part of the assembly/system, being of prime importance. As shown in Figure 14, three experimental techniques were used for validation: pressure sensitive paper, Digital Image Correlation and Optical Sensors. These techniques, FE and measured results will be discussed in more detail later but it is important to point out here that in order to achieve good correlation of the results, further material property measurements ('Input Data' stream) might be necessary. No matter which FEA method will be used in the following stages, to accurately analyse and predict brake squeal, a good correlation between simulation and test results is crucial, both in terms of modal characteristics and geometry representation. Bearing in mind the great number of component interactions taking place, considerable time was spent analysing in a robust and systematic manner which features and properties are playing a key role. In order to improve the FE prediction capabilities, the model complexity was increased step by step. Ultimately, once the correlation 
process is successfully completed, the output of Stage 2 is fully Validated FE 3D Brake Assembly Model, ready to be used for further analyses in Stage 3.

\subsection{Brake Assembly FE Model Synthesis}

Creating an FE mesh capable of preserving all the geometric details would need an element size so small that the simulation runtime would become practically unacceptable. On the other side, the geometry of all major components needs to be maintained, in order to avoid changes in frequencies and modes. Small fillets and radii of disc, pads and caliper, usually replaced with single steps and sharp corners for modelling simplicity, were not changed in this case. The final result was a model with an accurate representation, as shown in Figure 15.
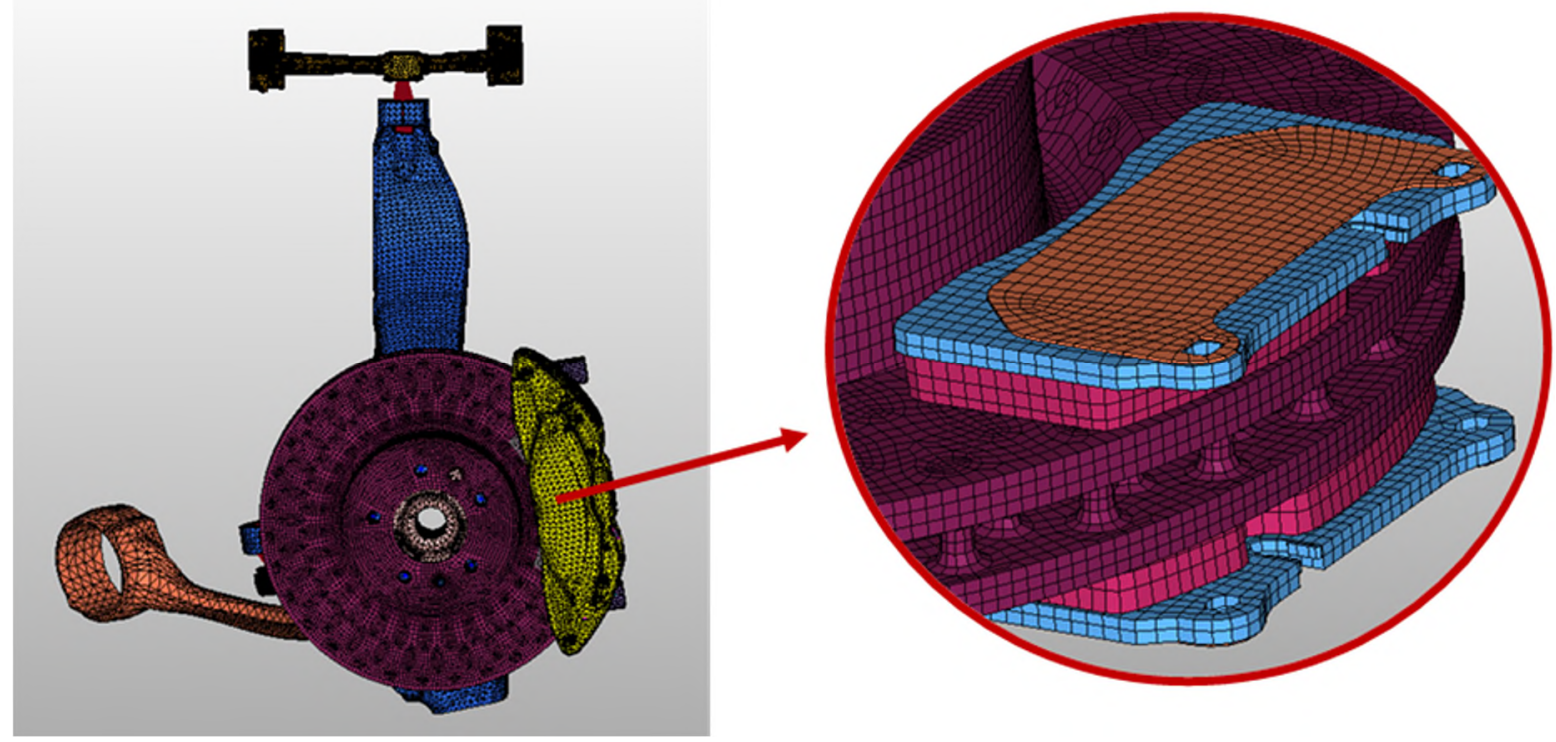

Figure 15: FE assembly model and disc/pad detail

Relatively small geometric errors and misalignments can influence the meshing procedure, leading to poor results. The original suspension corner model was therefore "cleaned" to ensure correct contact definition and parallelism between the surfaces, avoiding nodes penetration. In case of high frequency $(4-16 \mathrm{kHz})$ pads and rotor coupling has major impact, but at low frequency $(1-3 \mathrm{kHz})$ the influence of suspension components cannot be neglected. Links and tie rod were therefore included in the model (see Figure 15).

\subsection{Analyses and Validations}

Firstly, FE static analysis was run to check that the system was mechanically loaded in the correct way. The main steps can be summarised as follow:

1. An initial pre-load is applied to the pad spring clip;

2. The suspension corner is clamped up;

3. The hydraulic pressure is applied within caliper bores volume.

The brake pressure effect was created using hydraulic elements between the pistons and the caliper. In order to produce more stable pad contact, the hydraulic pressure was gradually increased from 2 to 100 bar. 


\subsubsection{Pad/disc Interface Pressure Distributions}

An overview of the assembly FE mesh, with pad/disc details is shown in Figure 4. Regarding the mesh adopted, the main advantage of using a mapped mesh with brick elements (C3D8R) is that the element type can be reduced in complexity ( $1^{\text {st }}$ order) to give the same level of accuracy, decreasing the CPU time. This element type can also be used for thermal analysis and gives good results in terms of pressure distributions at the discpad interface. Second order elements type C3D10 (10-node quadratic tetrahedron) were used where the geometry was exceptionally complex (e.g. caliper), giving the confidence that the frequencies variation was independent from the element size adopted during the analysis.

One of the most important mechanical interactions for any braking scenario is the pad/disc interface. The friction forces are created here and kinetic energy is transformed, through friction, into heat. Having the right contact pattern and pressure distributions is crucial to obtain good results in terms of temperature rise. For that reason the pressure distributions at the pad/disc interface were studied both experimentally and numerically, ensuring correct the initial boundary condition for the FE Thermo-Mechanical Analysis to follow in Stage 3.

An example of the interface pressure results obtained is presented in Figure 16, for the applied hydraulic pressure of 100 bar, in static conditions. Due to a relatively 'coarse', 'high grain size' friction material structure of the pad tested, a high level of filtering needed to be applied. Pressure distributions measured are very similar to the corresponding ones obtained using FE simulations, confirming the pressure peak values are moving towards the diagonal of the pad, instead of remaining concentrated near the piston-backplate contact region. The main difference between FE and measured results is related to the surface imperfections and asperities (showing "dotted" features) which are not modelled in ABAQUS, but the values and the overall pattern correlate quite well.

Pressure sensitive paper (PSP) technology is well established. Low cost combined with no special devices or equipment required, represents strong points of this technique, compared with other more complex sensors available on the market. The main limitation is each paper grade being able to measure only a certain pressure range. Furthermore, the paper can only be used in static conditions and at room temperature. Prescale Low Pressure (LW) paper, covering the wide range of interface pressures (25 - 100 bar), is the most suitable for studying brakes. Even if it can offer a "visual" direct imaging of pressure distribution and magnitude, an overall better visualization was achieved using the MATLAB code developed at Cranfield University. Paper (film) samples were scanned and processed using a specific MATLAB script, and finally compared to the FE results, showing a quite good correlation (see Figure 16). More information regarding the specific type of paper used (Fujifilm Prescale Film), its structure and operating principle, can be found in paper manufacturer's website (www.Fujifilm.com). 


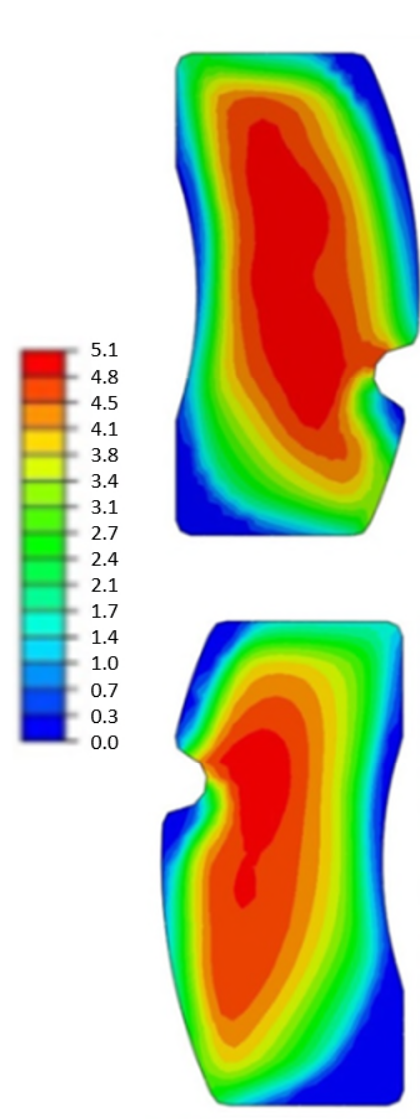

a)
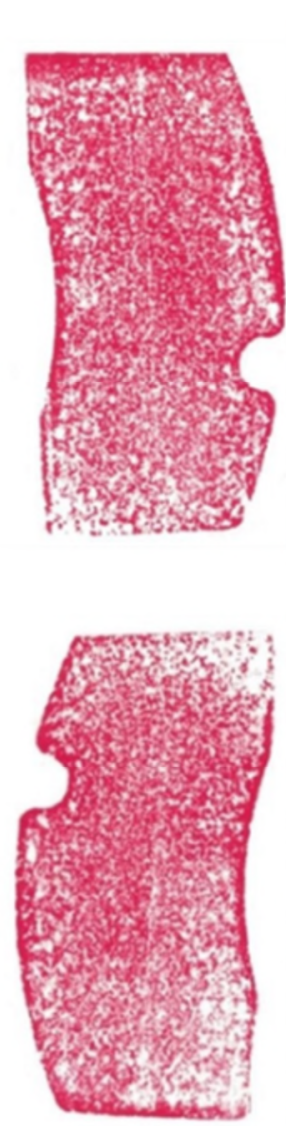

b)

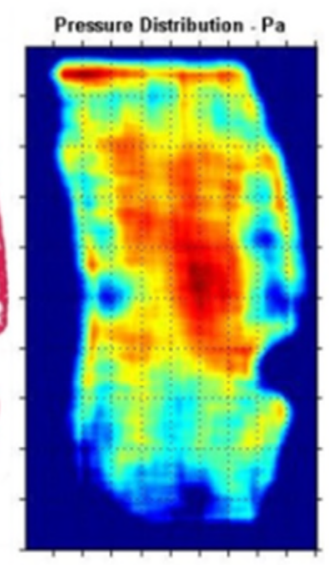

Pressure Distribution - $\mathrm{Pa}$

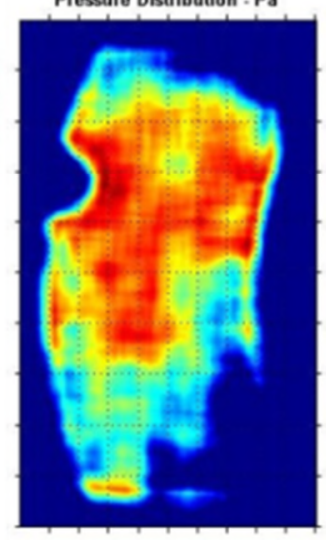

c)
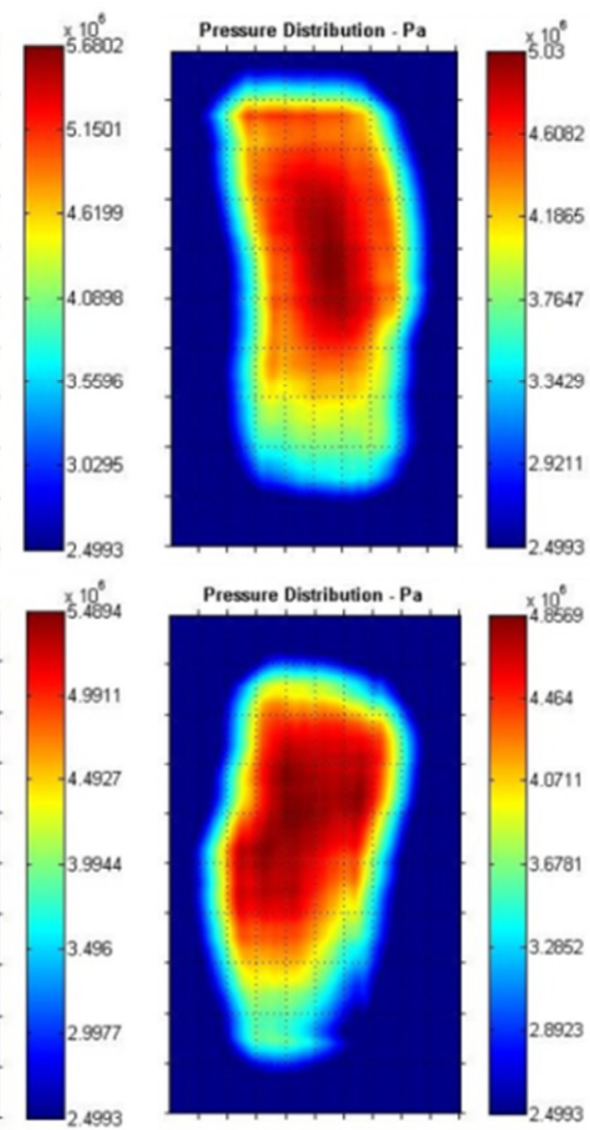

d)

Figure 16: Pad/disc static interface pressures for 100 bar hydraulic actuating pressure: a) FE results;

b) pressure sensitive paper imprints; c) and d) processed results with increased level of filtering

In order to advance pressure measurements, an initial attempt was made in using optical sensor technology. This technique offers the possibilities of measuring transient pressure, over a range of values and operating temperatures. Furthermore, if suitably installed, there is an opportunity to measure pressure in quasi dynamic and fully dynamic (actual) brake applications.

\subsubsection{Caliper deflection and strains}

In order to validate caliper deflections and strains, predicted using FE modelling, Digital Image Correlation experiments were conducted on the caliper installed in the vehicle corner, as shown in Figure 17. The methodology has been developed earlier on by Tirovic et al. [30] for analysing calipers subjected to actuating forces, with the loading here also including a quasi-dynamic case (with the braking torque applied with the loading arm and weights). The procedure applied is the same as explained for measuring friction material characteristics. The caliper was painted white and sparkled with black paint, monochromatic red light was used and the front of the caliper was in focus as seen by both cameras. The system was calibrated and the brake actuated by applying hydraulic pressure. 
Page $\mathbf{2 4}$ of 41

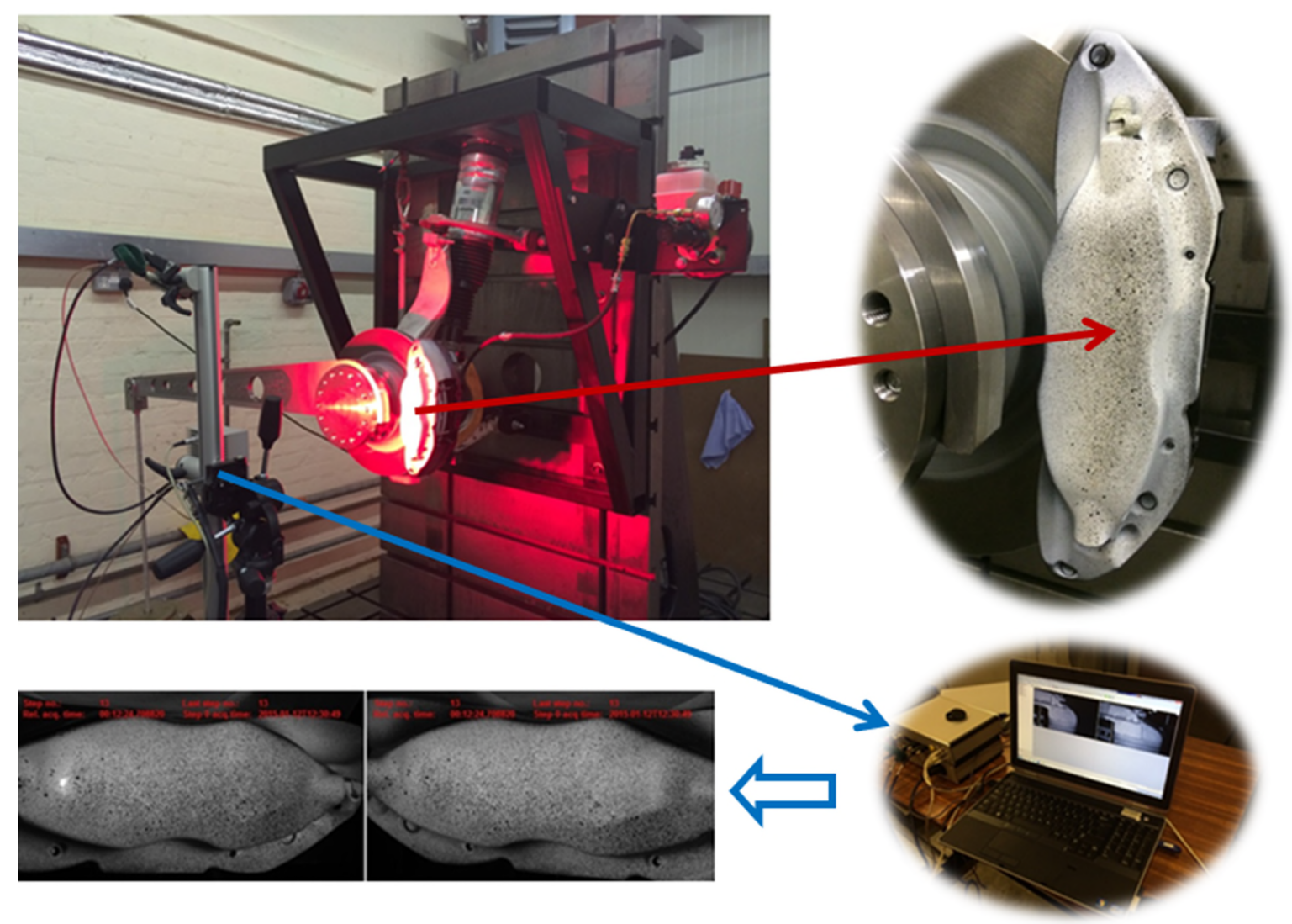

Figure 17: DIC measurements of caliper deflections and strains

Corresponding modelling (FE) and experimental (DIC) deflection results (in millimetres) are shown in Figure 18, for the front (outboard) side of the caliper. The rigid body motion has been removed. It can be seen that the displacement pattern is very similar. Maximum predicted (FE) value was $-0.15 \mathrm{~mm}$, which is only $0.02 \mathrm{~mm}$ less than measured (DIC) value of $-0.17 \mathrm{~mm}$. The difference is about $13 \%$, which might sound considerable, but it should be taken into consideration that the caliper has complex geometry and its deflection is also influenced by the deformation of other parts, predominantly pads.

In addition to static measurements when only hydraulic pressure was applied, quasi-dynamic tests were also conducted. Figure 17 shows the vehicle corner, complete suspension and braking assemblies, mounted onto a suitable frame bolted onto brake dynamometer head. The driveshaft has not been connected, giving free access to the assembly for measurements. Torsional loading of the assembly is achieved by the loading arm ( $1 \mathrm{~m}$ in length) bolted to the disc hub, which can take calibrated weights. Such a loading method is very simple, yet very accurate as the torque applied does not change with any component deformation. This is true all the way to the slip / breakaway point, when the disc starts rotating. The loading in such a manner is static, yet can be called 'quasi-dynamic' as a braking torque has been applied to the entire brake and vehicle corner but the disc does not rotate. The applied hydraulic pressure and torque can be controlled independently until the sliding begins. For such quasi-dynamic conditions, numerous tests were conducted using DIC equipment for measuring caliper deflections and strains. At the same time, optical fibre sensors were used to measure strain in the proximity of friction surface. 


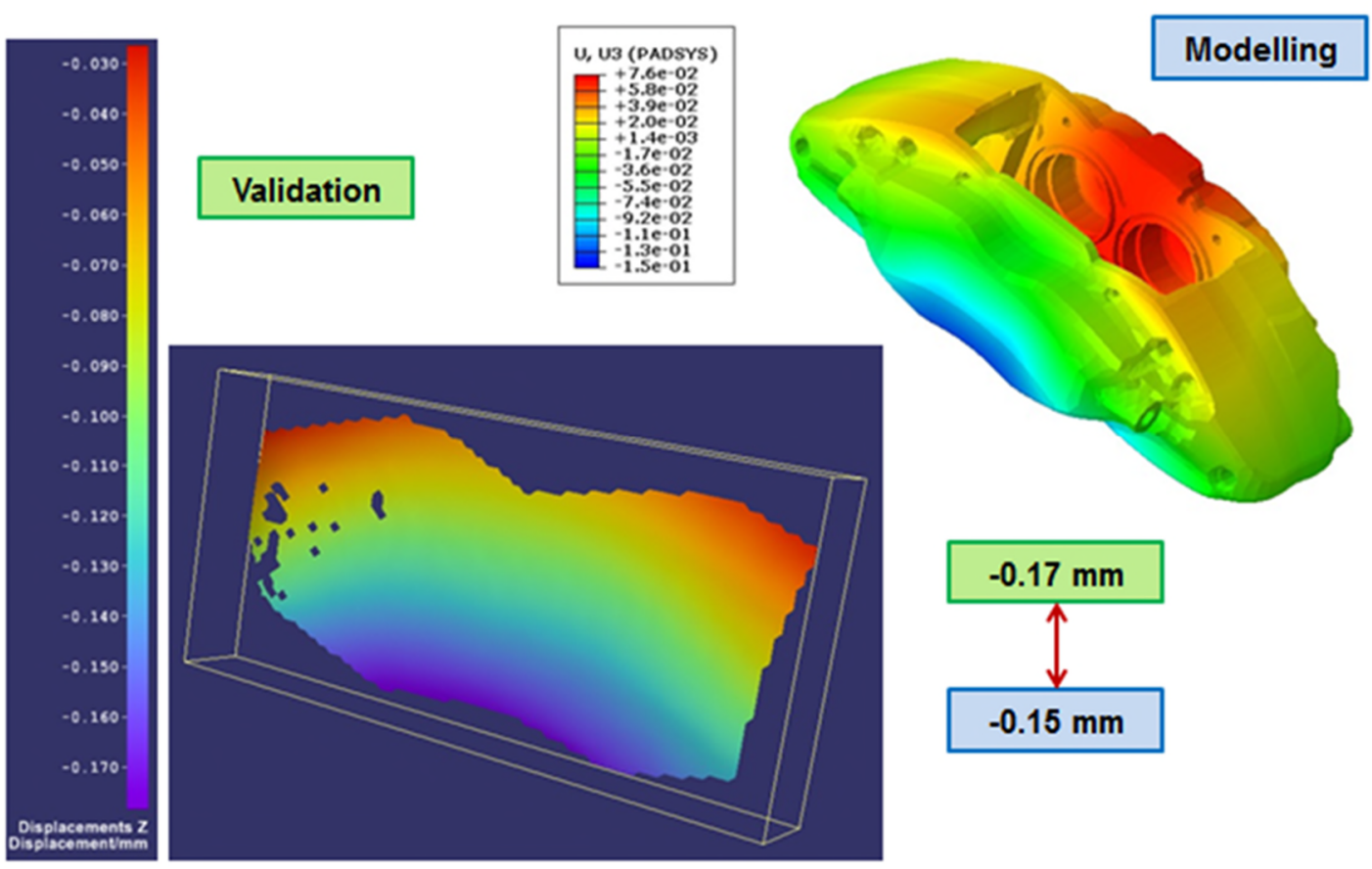

Figure 18: Caliper displacements: experimental (DIC) and calculated (FE) results

It is important to point out that the introduction of the braking torque in quasi-dynamic conditions had very little influence on caliper and pad strains, for the given actuating (hydraulic) pressure range. The reason is high caliper stiffness when exposed to 'in plane' loading resulting from the braking torque. In addition to the front of the caliper, bridge sections were also monitored and very small strain changes were also detected. These sections are very stiff, being "re-enforced" with the bolts fastening two caliper halves together. Similarly, optical sensors detected very little strain change in the pads with the introduction of quasi-dynamic braking torque. This is partly due to the relatively 'central' location of the strain sensors. No doubt edge effects would need to be studied further. All DIC and optical sensor measurements were in very close agreement with the results of FE analyses, which predicted very similar behaviour for both the caliper and pads.

\subsection{Stage 2: Summary}

Bases on the modelling and experiments conducted, most specifically interface pressure distributions and caliper deflections and strains, it can be concluded that brake assembly 3D FE mechanical model is fully validated and as output from Stage 2 (see Figure 14), can be used as a reliable input for thermo-mechanical analyses in Stage 3. The general conclusions can be summarised as follows:

1. The original suspension corner model needs to be "cleaned" to ensure correct contact and parallelism between the surfaces (pad/disc and pistons/backplate interfaces, caliper bores and pad/caliper abutments). Even very small inaccuracies in contact definition will negatively affect pressure distributions and consequently the heat generated in the Thermo-Mechanical Analyses (Stage 3), decreasing the quality of the results obtained; 
2. The "cleaning" procedure needs to be coupled with an improved mesh in critical areas, to reduce the CPU time and increase the accuracy, in particular regarding pressure distributions prediction;

3. Digital Image Correlation experiments (caliper strains), represents an indirect validation of the pressure distributions and very useful tool in validating the deflection of caliper and full suspension corner, both in static and quasi-dynamic conditions.

\section{Stage 3: Brake Assembly Thermo-Mechanical FE Analysis}

Stage 3 flowchart is shown in Figure 13, having also three main streams: Input Data, Modelling and Validation. The main input is from Stage 2, a fully validated FE 3D Brake Assembly Model. Additionally, further material property data is required, as in this Stage the modelling loading conditions are for higher than ambient temperatures. For all major brake assembly parts - the disc, caliper and pads, material characteristics as a function of temperature are vital for realistic modelling. In addition to mechanical characteristics (Young's modulus, Poisson's ratio and density), particularly important are changes with temperature for thermal conductivity, specific heat capacity and coefficient of thermal expansion.

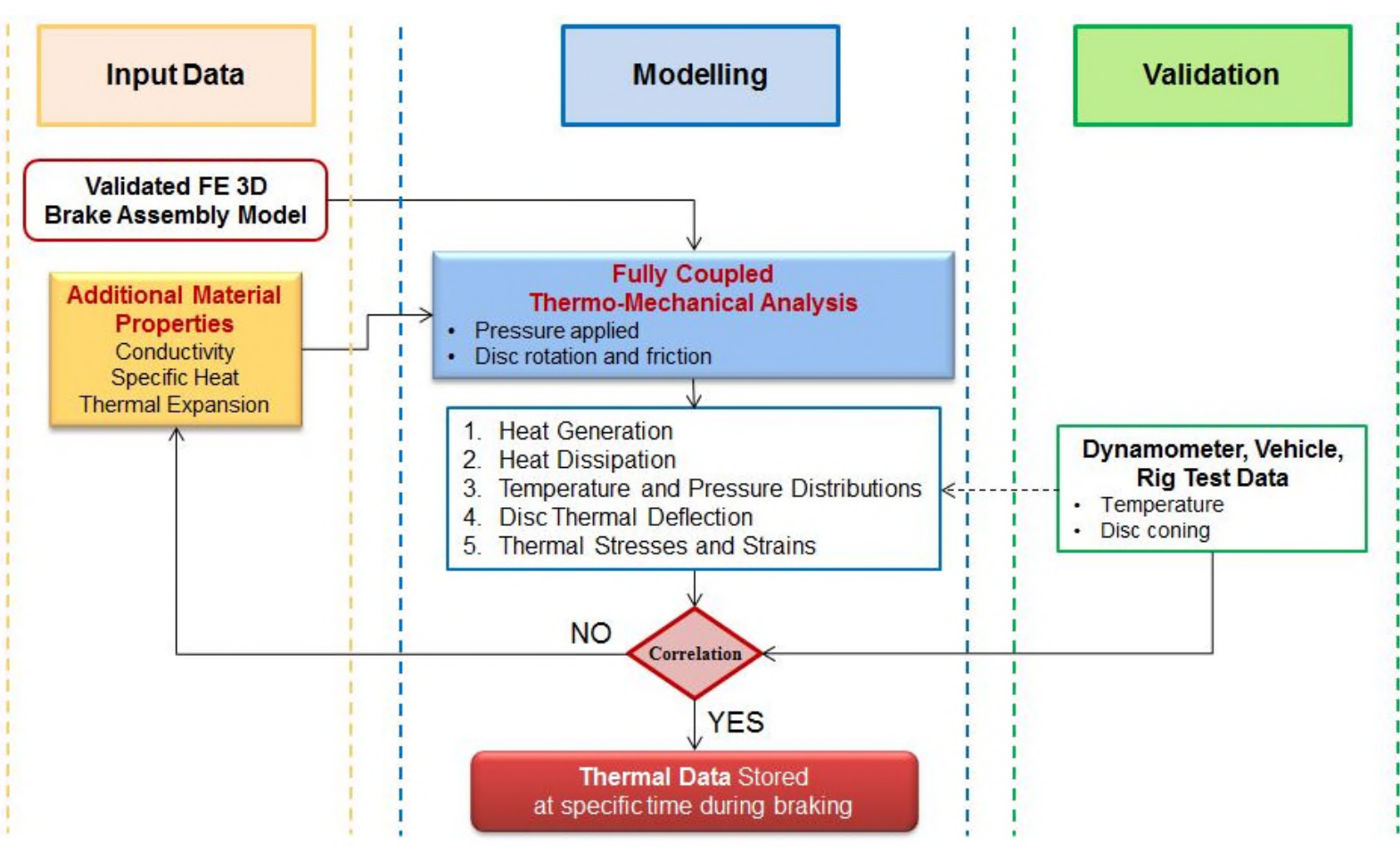

Figure 19: Stage 3 flowchart: Brake Assembly Thermo-Mechanical FE Analysis

In addition to previously shown material characteristics, additional material properties of brake components are summarized in Table 7, with Table 8 showing changing disc material properties with temperature. 
Page 27 of 41

\begin{tabular}{|c|c|c|c|c|c|c|c|}
\hline Component & $\begin{array}{c}\text { Material / } \\
\text { type } \\
\text { Modulus } \\
{[\mathbf{G P a}]}\end{array}$ & $\begin{array}{c}\text { Youisson's } \\
\text { Ratio } \\
{[-]}\end{array}$ & $\begin{array}{c}\text { Mass } \\
\text { Density } \\
{\left[\mathbf{k g} / \mathbf{m}^{3}\right]}\end{array}$ & $\begin{array}{c}\text { Thermal } \\
\text { Conductivity } \\
{[\mathbf{W} / \mathbf{m K}]}\end{array}$ & $\begin{array}{c}\text { Specific } \\
\text { Heat } \\
{[\mathbf{J} / \mathbf{k g K}]}\end{array}$ & $\begin{array}{c}\text { Coefficient } \\
\text { of Thermal } \\
\text { Expansion } \\
\mathbf{1 0}^{-6}\left[\mathbf{K}^{-1}\right]\end{array}$ \\
\hline Disc & $\begin{array}{c}\text { Grey Iron } \\
\text { GG150 }\end{array}$ & 110.7 & 0.245 & 6900 & 62 & 525 & 10.1 \\
\hline Caliper & $\begin{array}{c}\text { Aluminum } \\
\text { Alloy }\end{array}$ & 71 & 0.33 & 2720 & 190 & 900 & 22.0 \\
\hline $\begin{array}{c}\text { Pad/ } \\
\text { Backplate }\end{array}$ & Steel & 210 & 0.29 & 7820 & 32 & 595 & 11.7 \\
\hline $\begin{array}{c}\text { Pad/ Friction } \\
\text { Material }\end{array}$ & Organic & $0.59-3.34$ & $0.14-0.30$ & 2670 & 0.9 & 1500 & 18.0 \\
\hline
\end{tabular}

Table 7: Brake component material properties at $20^{\circ} \mathrm{C}$

\begin{tabular}{|c|c|c|c|c|c|}
\hline $\begin{array}{c}\text { Temperature } \\
{\left[{ }^{\circ} \mathrm{C}\right]}\end{array}$ & $\begin{array}{c}\text { Young's } \\
\text { Modulus } \\
{[\mathbf{G P a}]}\end{array}$ & $\begin{array}{c}\text { Poisson's } \\
\text { Ratio } \\
{[-]}\end{array}$ & $\begin{array}{c}\text { Thermal } \\
\text { Conductivity } \\
{[\mathbf{W} / \mathbf{m K}]}\end{array}$ & $\begin{array}{c}\text { Specific } \\
\text { Heat } \\
{[\mathbf{J} / \mathbf{k g K}]}\end{array}$ & $\begin{array}{c}\text { Coefficient of Thermal } \\
\text { Expansion } \\
\mathbf{1 0}^{-\mathbf{6}}\left[\mathbf{K}^{-1}\right]\end{array}$ \\
\hline 20 & 110.7 & 0.245 & 62 & 525 & 10.1 \\
\hline 100 & 99.3 & 0.193 & 63 & 565 & 11.1 \\
\hline 200 & 101.0 & 0.157 & 64 & 602 & 11.7 \\
\hline 300 & 102.0 & 0.140 & 62 & 640 & 12.7 \\
\hline 400 & 99.3 & 0.139 & 59 & 672 & 12.7 \\
\hline 500 & 90.8 & 0.149 & 53 & 750 & 12.9 \\
\hline
\end{tabular}

Table 8: Disc material properties change with temperature

Disc and friction material properties and their change with temperature and strain have a major effect on brake behavior. These changes, as shown in Tables 7 and 8, are very complex and influence, in different manner, the brake behaviour when compared to the results obtained using 'average' material characteristics over the considered temperature and strain range.

Combining this aspect with the "rotating heat source effect", which occurs in real braking situations, provides much more realistic predictions of brake squeal than the standard isothermal analyses, as also mentioned in the latest work published by Hassan et al. [18]. Another advantage of this procedure is the possibility to obtain not only realistic boundary conditions for the future instability analysis, but also important information on thermal coning. The model is allowing the analyst to investigate at the same time braking performance and NVH aspects.

\subsection{Finite Element Modelling and Validation}

Prior to running thermal analyses of the entire brake assembly, thermal analyses were run for separate disc and pad models. This was to insure mesh and analysis suitability and initially assess the validity of the results. After this initial check, several types of brake applications (duties) were modelled for the entire brake assembly. The common approach can be summarised in the following: 
1. The hydraulic pressure is applied within caliper bores volume;

2. The rotational velocity is applied to the disc (a rigid body connector was used to link the top hat section of the disc to its axis of rotation);

3. The heat generation is proportional to the local sliding velocity and generated frictional force, so it is a function of the pressure at the pad/disc interface and of the coefficient of friction. No wear effects were modelled at this stage.

4. Heat dissipation characteristics were obtained from dynamometer tests, for the disc rotating in the cross flow. Cooling curves for specific duties were measured and heat transfer coefficients for all three heat dissipation modes - convection, conduction and radiation extracted and suitably modelled. As the speed is constant and temperatures are relatively low, a convective heat transfer coefficient was a linear function of temperature, reducing from $120 \mathrm{~W} / \mathrm{m}^{2} \mathrm{~K}$ at $20^{\circ} \mathrm{C}$ to around $110 \mathrm{~W} / \mathrm{m}^{2} \mathrm{~K}$ at $200^{\circ} \mathrm{C}$. Emissivity was considered constant at 0.55 . Conductive heat losses are exceptionally low, as the disc is initially cold and the braking duty is not too severe, with braking time relatively short. Consequently, the conduction into the top hat is small and there is hardly any temperature rise at the disc top hat flange, hence no gradients toward the vehicle hub and wheel. To enable heat flow through these areas and keep the modelling simple, a conductive heat transfer coefficient was used identical to the convective values at the disc rotor areas exposed to cross flow. It must be noted here that the total heat dissipation is low, with no practical influence on the results. Heat generation is higher by several order of the magnitude, brake application time is short (10 seconds) and the temperatures reached are relatively low. The major influences on temperature distribution (hot banding) are the result (in addition to heat input, i.e. braking duty) of pad/disc interface, pressure distributions and disc coning. All these effects were changing during braking.

In order to simulate the contact between the disc and pads, the surface-to-surface contact interaction was used. Of the methodologies available in ABAQUS, it is the only one allowing heat conduction and it also permits the determination of the contact pressure distribution, which is the starting point for the Complex Eigenvalue Analysis. Regarding the contact scheme, the condition of finite sliding was adopted, with frictional sliding behaviour simulated by the penalty method. The friction coefficient variation with temperature was also taken into account. For all the parts in contact (caliper/pads abutments, pistons/backplate, disc/hub, springs, etc.) the same surface-to-surface contact interaction was used, but finite sliding was replaced with small sliding, which limits the contact to a predefined area, due to the small movement involved.

For illustration purposes, a drag braking results will be presented. As specified in Table 9, a drag brake application was modelled, for the front brake. This duty was selected as a reasonably severe to heat up the disc relatively quickly and uniformly to moderately high temperatures (about $250^{\circ} \mathrm{C}$ ), generating some thermal gradients but avoiding high temperatures and high thermal gradients. Such duties were conducted on the dynamometer and the vehicle and were found to be repeatable and reliable in analysing the squeal phenomenon. 
Tirovic-Vianello-Bannister - 5 December 2017

Page 29 of 41

\begin{tabular}{|c|c|}
\hline \multicolumn{2}{|c|}{ Vehicle characteristics } \\
\hline Vehicle mass $(\mathrm{m})$ & $3200 \mathrm{~kg}$ \\
\hline Brake force distribution $\mathrm{F}: \mathrm{R}$ & $68: 32$ \\
\hline \multicolumn{2}{|c|}{ Brake application characteristics } \\
\hline Vehicle speeds $(\mathrm{V})$ & Constant $=100 \mathrm{~km} / \mathrm{h}$ \\
\hline Duration of brake application $\left(\mathrm{t}_{\mathrm{a}}\right)$ & $10 \mathrm{~s}$ \\
\hline Hydraulic pressure $\left(\mathrm{p}_{\mathrm{h}}\right)$ & $30 \mathrm{bar}$ \\
\hline
\end{tabular}

Table 9: Drag brake application modelled

Figure 20 shows disc and pad temperatures at $1 \mathrm{~s}, 5 \mathrm{~s}$ and at the end of the drag, after $10 \mathrm{~s}$. The history output for caliper and suspension components was not requested in the post-processing, to speed up the simulation and more clearly show disc temperatures. A non-uniform disc friction surface heating is evident. This is a result of the interface pressure distribution and its change during braking. Sliding speeds at different disc radii and disc coning have additionally affected heat generation and disc temperatures - a very obvious hot banding developed approximately in the middle of the rubbing path. As mentioned earlier, it should be noted that the wear was not modelled. Considering a relatively short brake application modelled and relatively low temperatures, wear effects were not considered as they are unlikely to affect the results obtained. It should be also pointed out that heat dissipation was modelled but influenced the results very little, again, due to short time and relatively low temperatures. The maximum disc temperature predicted was (Figure 20 ) $251^{\circ} \mathrm{C}$, at approx. the mean swept radius. Large variation of the temperatures radially across disc friction surface can be observed, with disc inner (ID) and outer (OD) diameters running nearly $100^{\circ} \mathrm{C}$ cooler.

The above temperature results were confirmed in dynamometer tests for newly bedded-in brakes. In consecutive applications, due to the pad wear influence, this hot band tends to move. Vehicle temperature results are more variable, due to less control on the bedding in process and environmental effects. Obviously, in real driving conditions, braking duties will considerably vary in terms of initial and final braking speed, temperature and applied actuating (hydraulic) pressure. Wear can be considerable and its influence pronounced in cumulative terms but also in single heavy duty applications owning to the thermoelastic instability effects. Ostermeyer and Graf [31] successfully modelled hot banding including wear and temperature. This effect has substantial influence not only on NVH but also brake performance.

It is worth pointing out that temperature contour shown in Figure 20, predicted using the entire brake assembly, differ quite considerably from the temperatures predicted using disc only and assuming uniform (or otherwise pre-defined) heat flux distribution over the friction surface. These effects are of prime importance. In the considered case, heat conducted to the pads and dissipated to the environment has relatively minor (secondary) effect but disc non uniform radial heating is crucial for obtaining realistic results. Obviously such analysis is very computing intensive and has been run on a supercomputer. 


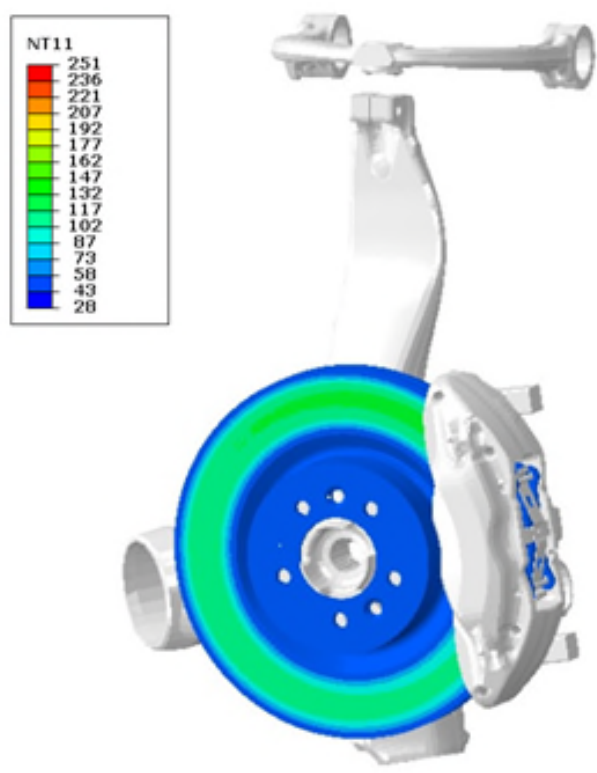

a)

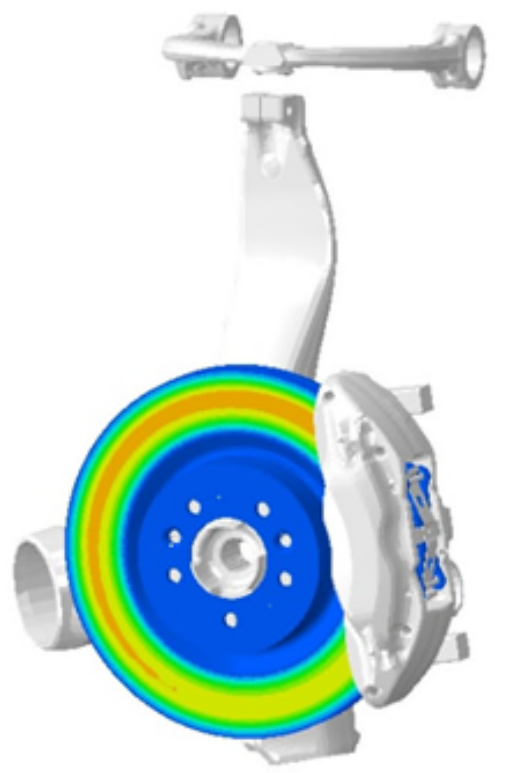

b)

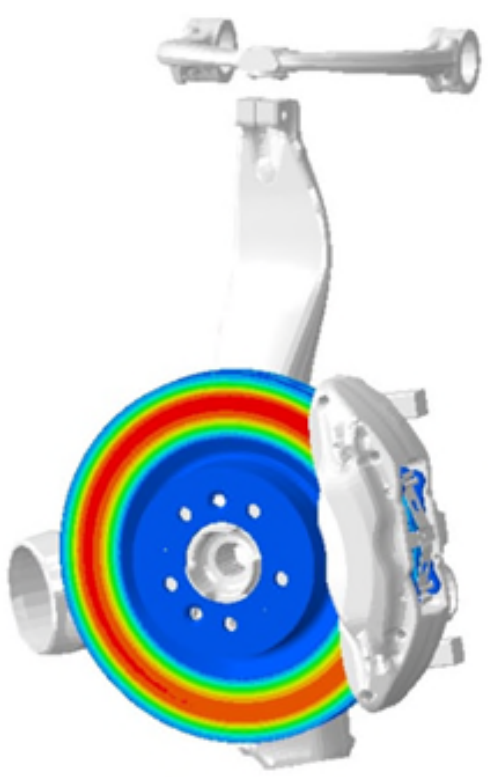

c)

Figure 20: Evaluation of disc temperature profile during drag brake application at: a) 1 second;

b) 5 seconds; c) 10 seconds

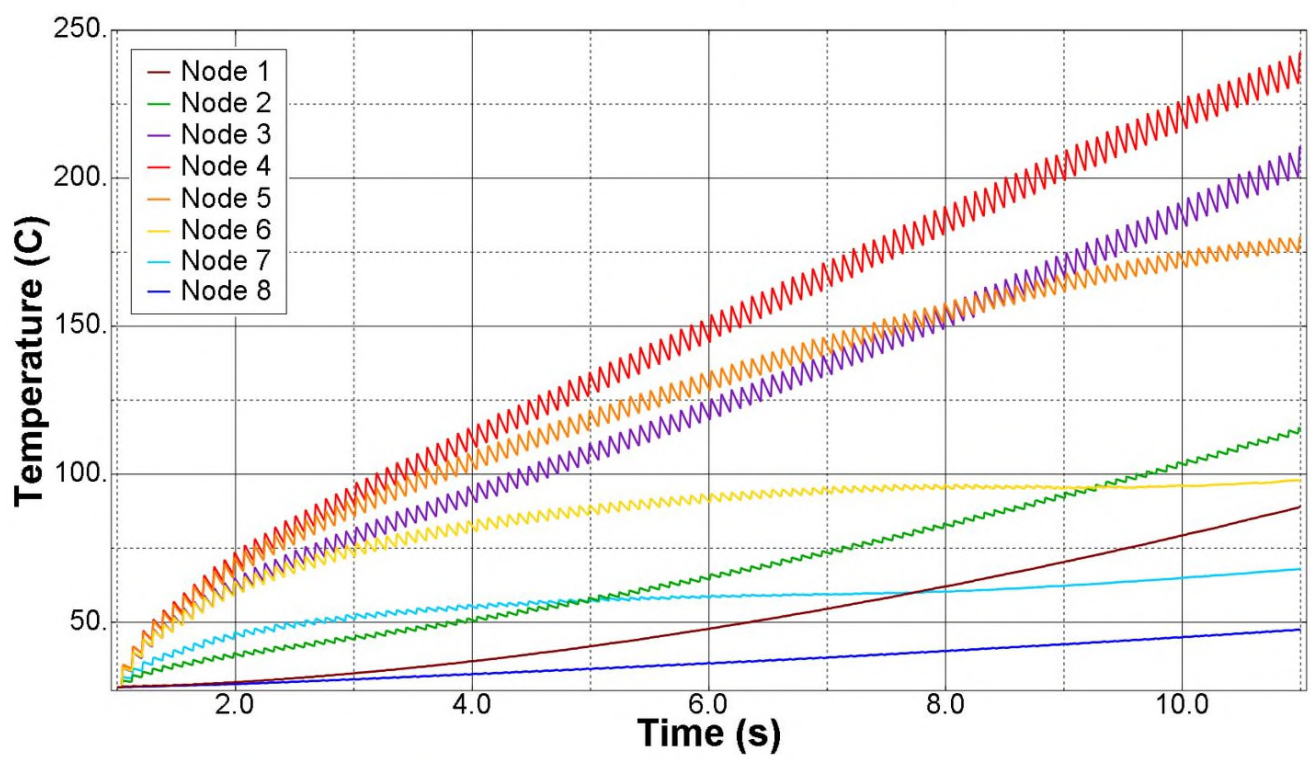

a)

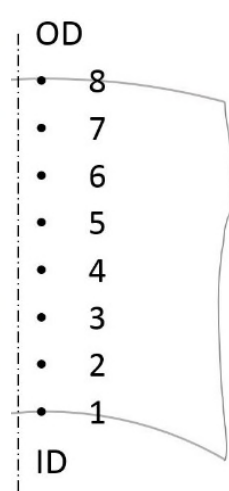

b)

Figure 21: a) Nodal temperatures during 10 seconds drag brake application; b) Node positions

Figure 21a shows temperature history plots for the outboard side of the disc throughout the 10 seconds drag application. The nodes 1 to 8 are equally spaced between disc inner (ID) and outer (OD) diameters, as shown in Figure 21b. Hot band migration can be clearly seen, as the temperatures increase at various rates across the friction surface. Node 4 in proximity to the mean swept radius shows consistently the highest temperatures. 
Node 5 (positioned towards the OD from node 4) has initially higher temperatures but at approximately 8 seconds into the drag, node 3 (positioned towards the ID from node 4) equalised the temperature with node 5 and then reaches approximately $25^{\circ} \mathrm{C}$ higher temperatures. Similar 'inversion' can be seen between nodes 6 and 2, as well as 7 and 1. It should be noted that inboard disc surface has expressed similar effects but somewhat different temperature banding.

Disc deformation caused by the hydraulic application pressure of 30 bar is combined with the effect of the thermal loading. The cumulative thermal and mechanical axial deformation (coning) is presented in Figure 22, indicating a coning of about $0.1 \mathrm{~mm}$ at the disc/pad contact area, increasing to $0.165 \mathrm{~mm}$ at the diametrically opposite position. Conducted measurement's on brake dynamometer, using capacitive displacements transducers, confirmed disc behaviour shown in Figure 21.

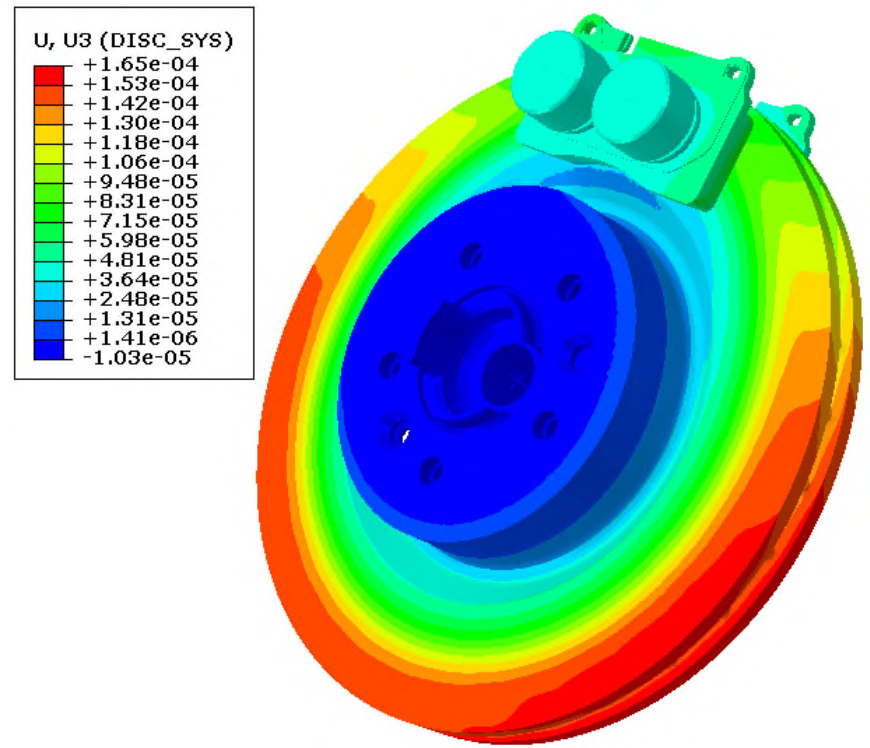

Figure 22: Disc axial deflection (in metres), at the end of the drag (at 10s)

\subsection{Stage 3: Summary}

A Fully Coupled Thermo-Mechanical analysis has been established to take into account both thermal and structural effects, before running the instability analysis using the complex eigenvalue method (CEA). The process is conducted and the effects can be interpreted as follows:

1. Pads are pressed against the disc which is rotated and the heat is generated at the interface pad/disc as a result of friction and imposed relative pad/disc motion;

2. The 'rotating heat source' effect is evident and the non-axisymmetric rotor temperature distribution can be observed, together with the thermal coning and caliper mechanical effect;

3. Thermal results output from Stage 3 (see Figure 20) are therefore ready to be used in the final Stage 4, for assessing brake assembly instabilities. 


\section{Stage 4: Brake Assembly Instability Analysis}

The final, Stage 4 in squeal propensity investigation, is schematically shown in Figure 23. As in previous stages, there are three streams, Input Data, Modelling and Validation. The instability analysis of the full brake assembly is based on the well know Complex Eigenvalue Analysis (CEA), with the sign of the real part giving an indication of stability and the imaginary part defining the frequency of the unstable mode. Non-linear input can be used for thermal analysis, but not for the complex eigenvalue analysis.

As mentioned before, results of the thermo-mechanical analysis, which provide the information of the area in contact at the pad/disc interface and the consequent pressure distributions, have been saved in the output file. In Stage 4 the stability analysis can access those results at discrete times during braking, enabling the inclusion of thermal effects within the vibrational analysis. This is actually taking a snapshot of the heated and deformed brake assembly, for running the instability analysis. The final output is a Validated Thermo-Mechanical 3D FE NVH Model in which natural frequencies and modes, instabilities and contribution factors can be predicted at any time during a specific brake application, giving realistic insight into the instabilities of the complete brake assembly under operating conditions.

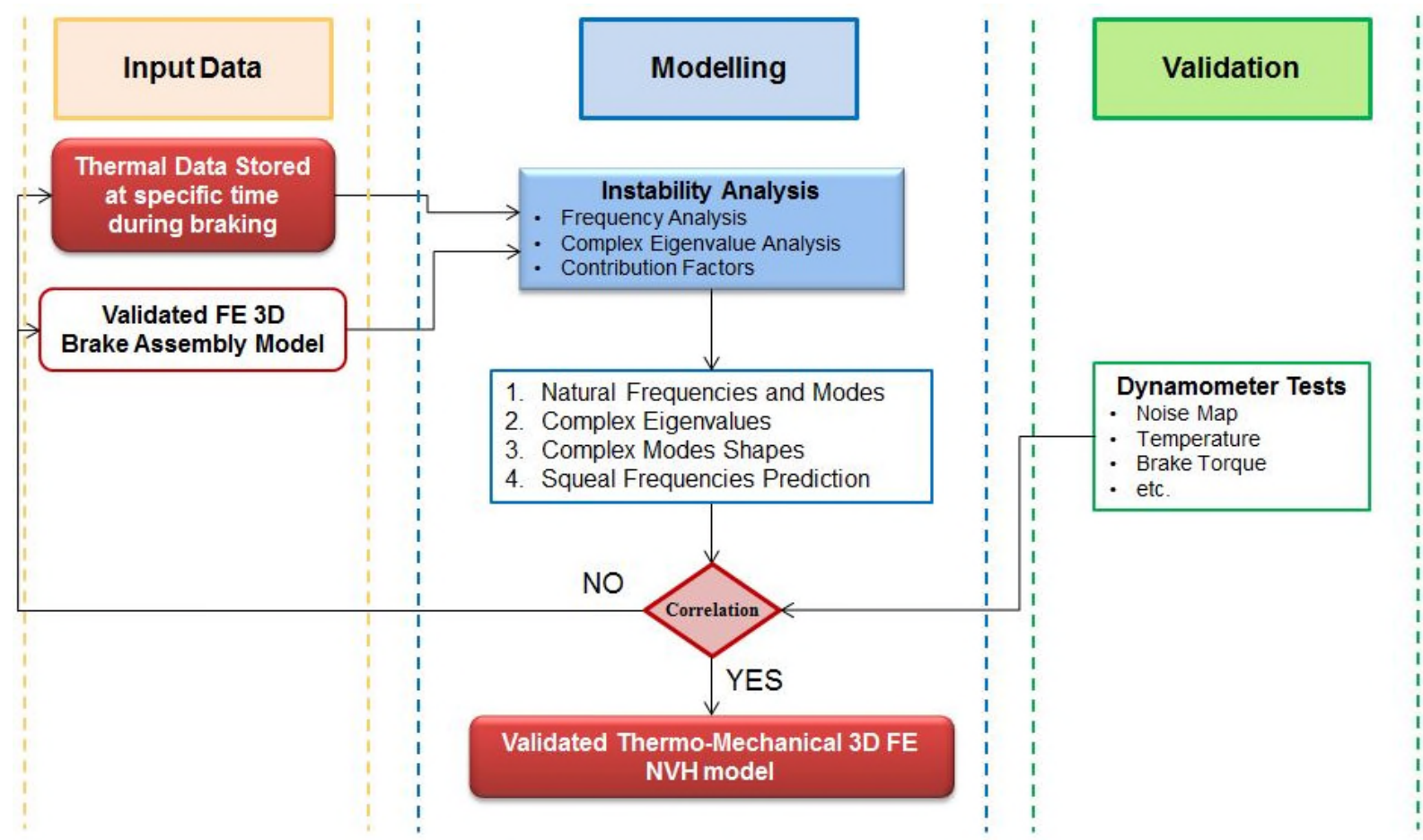

Figure 23: Stage 4 flowchart: Brake Assembly Stability Analysis

\subsection{Complex Eigenvalue Analysis Method}

In order to investigate squeal phenomenon, Complex Eigenvalue Analysis was introduced by Liles [32], adopted and further developed by other authors including Shi et al. [33]. The essence of this method lies in the inclusion of an asymmetric friction matrix derived from the results of the contact pressure analysis, and caused by frictional coupling at the disc-pad interface. The method predicts the complex eigenvalues, with the 
sign of the real part providing an indication of stability and the imaginary part defining the corresponding frequency.

The main advantage of this technique, compared to transient analysis, is the possibility to find all unstable frequencies in one run, for a set of operating conditions. It is, therefore, a very efficient method. On the other hand, over prediction represent the main disadvantage, which cannot be neglected during the post-processing of the results obtained.

As shown by Kung et al. [19] the entire procedure can be implemented in ABAQUS and is divided into four main steps:

1. Non-linear contact analysis, in which the braking system is mechanically loaded (hydraulic pressure and all pre-loads applied). Pads are pressed against the disc and static pressure distribution can be identified;

2. Non-linear contact analysis with rotation, where rotational velocity is applied to the disc to allow the introduction of friction forces at the pad/disc contact interfaces. In this way, dynamic change in pressure distributions is taken into account;

3. Frequency analysis, where natural frequencies and corresponding modes of the un-damped system are extracted;

4. Complex eigenvalue analysis, final step which represent the actual instability analysis. The coupling effect of friction is included and complex eigenvalues and relative complex mode shapes are extracted, and the squeal propensity of the braking system is analysed.

\subsection{Complex Eigenvalue Extraction at Room Temperature}

Following the procedure mentioned above, the complex eigenvalues and unstable modes were initially extracted at room temperature, for the 'cold' brake. It should be noted that brake squeal is predominantly happening at low speeds and actuating pressures. Occurrence of squeal is more likely after medium duty brake application, as thermally modelled in previous section. However, for initial investigations brake was considered to be cold, with thermal effects being introduced later. Figure 24 gives an overview of the results obtained. Varying the rotational speed from 5 to $15 \mathrm{~km} / \mathrm{h}$ was found to have a very small effect on squeal propensity, so results presented are related to the speed of $10 \mathrm{~km} / \mathrm{h}$. Confirming the conclusion of other researchers, the main influence was observed as a result of the variation of coefficient of friction and pressure applied. Increasing the friction coefficient at the pad/disc interface showed an increase of the squeal propensity while the contact variation due to different actuation pressures (5,10 and 20 bar), was responsible of changing the pick value of the real part for the unstable modes extracted.

The instability analysis carried out using the complex eigenvalue analysis predicts the squeal appearance for the present vehicle corner, in the range of $1 \mathrm{kHz}$ to $10 \mathrm{kHz}$. Seven different unstable frequencies were observed at a constant speed of $10 \mathrm{~km} / \mathrm{h}:$ 893, 2005, 3065, 6060, 6650, 8530 and $9560 \mathrm{~Hz}$. As mentioned before, one 
limitation of this technique is the over prediction, so not every pick will end up as a noisy frequency. However the instability around $3 \mathrm{kHz}$ and between 6 and $7 \mathrm{kHz}$ is clearly revealed for all the operating conditions analysed.

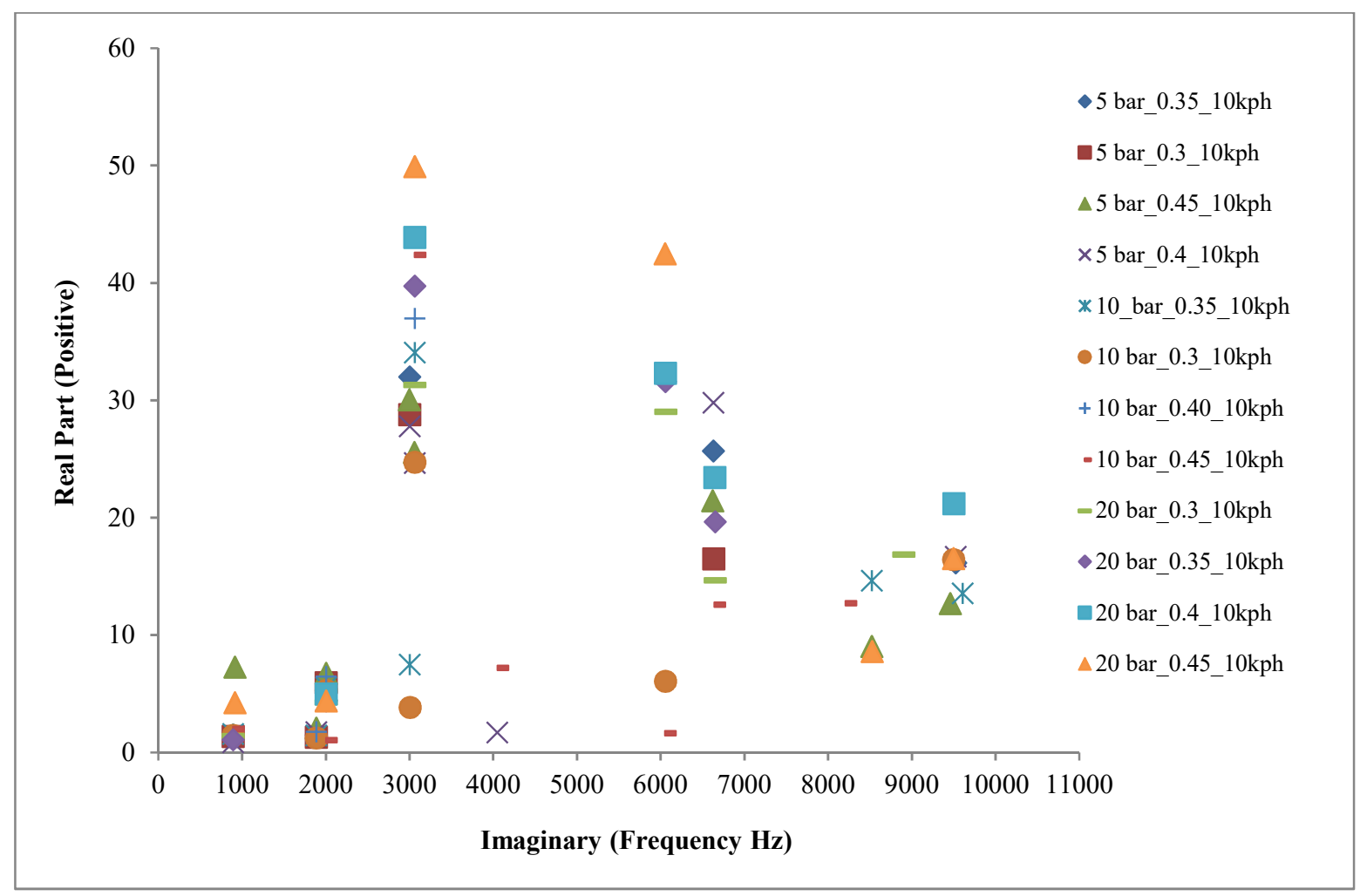

Figure 24: Instabilities and vibration frequencies for the cold brake assembly

\subsection{Results Comparison with the Dynamometer Test SAE J2521}

In order to validate the simulation, the unstable frequencies predicted with the FE model (Figure 24) are compared with the results of the SAE J2521 tests (conducted on Jaguar Land Rover dynamometer) in Figure 25. The main unstable frequencies are presented in both analyses, showing a good agreement between numerical and experimental data. Indeed, squeal appears at frequencies of around $3 \mathrm{kHz}$ and $6 \mathrm{kHz}$. 

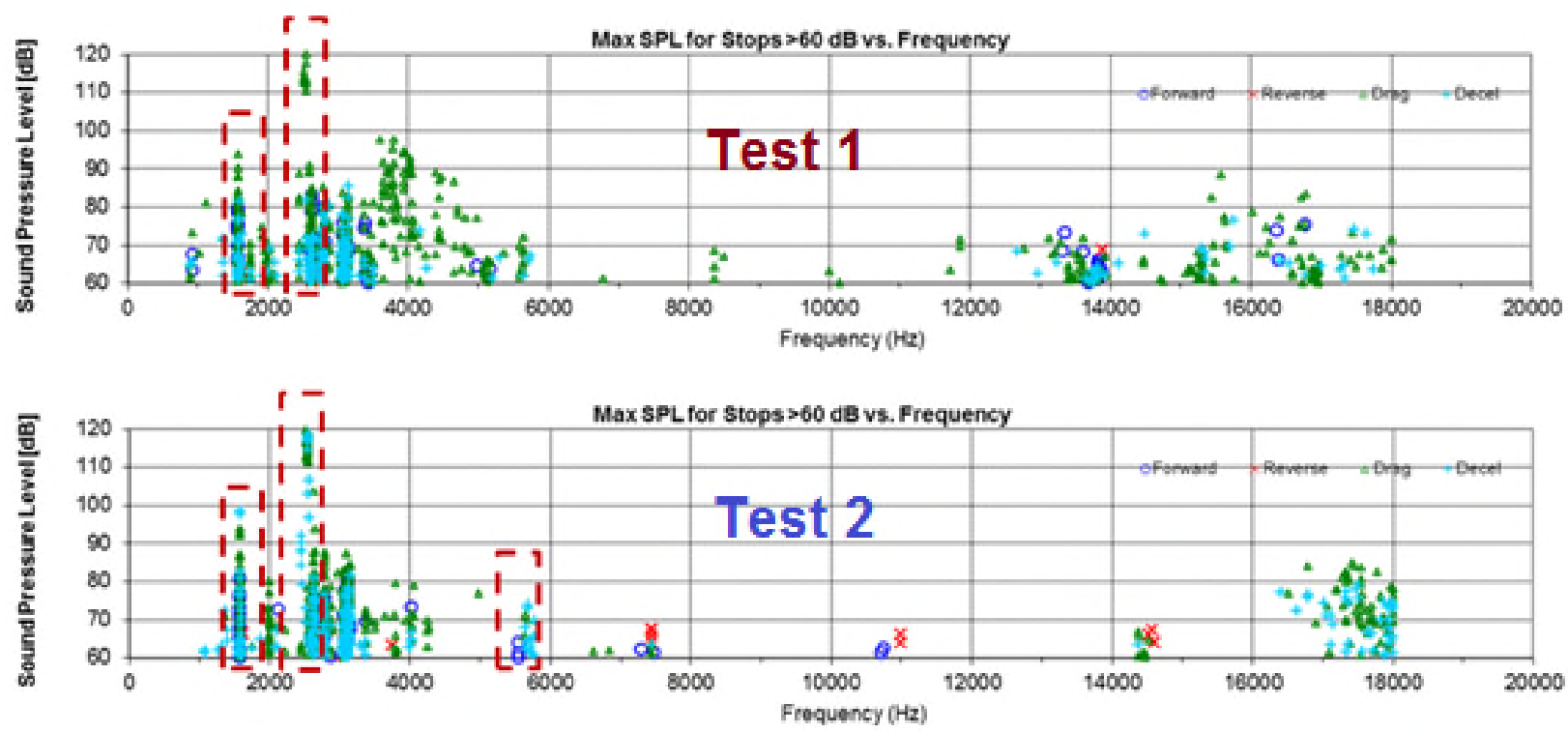

Figure 25: Dynamometer Tests Results (to SAE J2521, JLR Internal Report)

\subsection{Contributing Factors}

Another advantage of CEA is the possibility of identifying relevant mode shapes and components which combined can create the instability (contribution factors). In this way modifications can be introduced to separate components modes apart, avoiding the modal coupling responsible for squeal generation. In Figure 26 is possible to visualise the unstable mode at around $3 \mathrm{kHz}$ in which the major contributor is the caliper (with blocks) and knuckle. For every unstable frequency is therefore possible to obtain all the necessary information, including the mode shape that can be compared with the experimental results obtained using a laser vibrometer. 


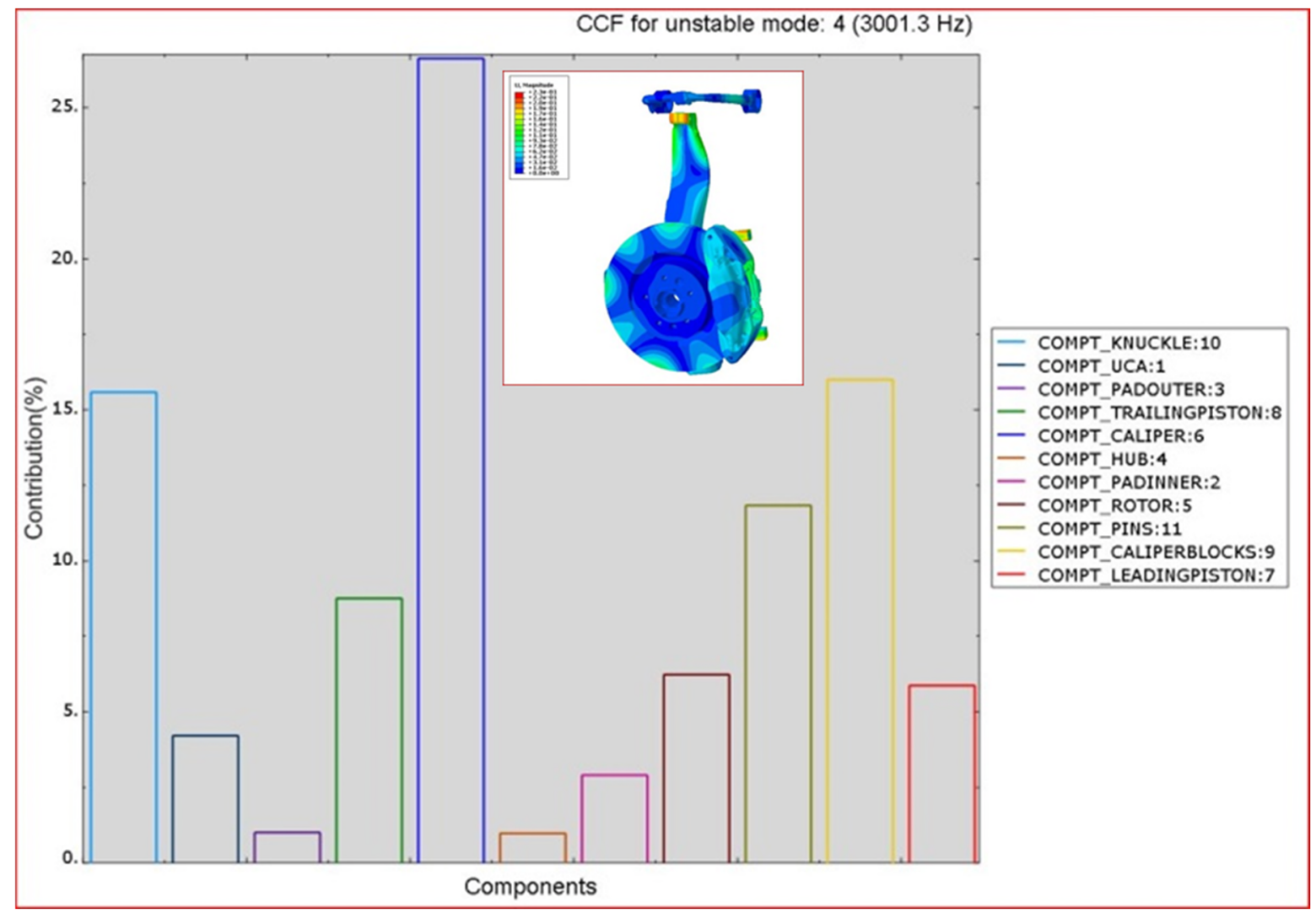

Figure 26: Example of unstable mode at approximately $3 \mathrm{kHz}$ and contribution factors

\subsection{Effects of Temperature on Noise Propensity}

After the validation at room temperature, the final stage is represented by the eigenvalue extraction taking into account the effects of temperature:

1. Variation in contact and pressure at the pad/disc interface, as consequence of disc thermal coning;

2. Changing of material properties with temperature;

In order to implement those effects, the output file generated at the end of the thermo-mechanical simulation was used (as explained in section 6.1), providing the thermal boundary conditions, before running the instability analysis. The fugitive nature of squeal and its dependence upon the thermo-mechanical interaction at the friction interface can be finally observed by comparing the Instability analysis results with and without the effect of temperature. Overall, the number of unstable modes increases with increase in friction level. The modes predicted by the isothermal case are also reflected in those modes determined by using the fully coupled thermo-mechanical analysis in which the contact at the pad/disc interface changes with time. This time dependency can cause the frequency of an unstable mode to shift, but more often it does cause change in the magnitude of the real part of the eigenvalue. In some cases a mode is no longer unstable whilst in others, the variation in contact is responsible for the generation of a new unstable mode. If the magnitude of the real part of the eigenvalue is taken to reflect the squeal propensity of the brake, then the results presented in Figure 27 show that the squeal propensity can either increase or decrease with time. It should be noted that FE modelling 
did not cover all the duties the brake was tested to (J2521), which included forward, reverse, drag and decal brake applications.

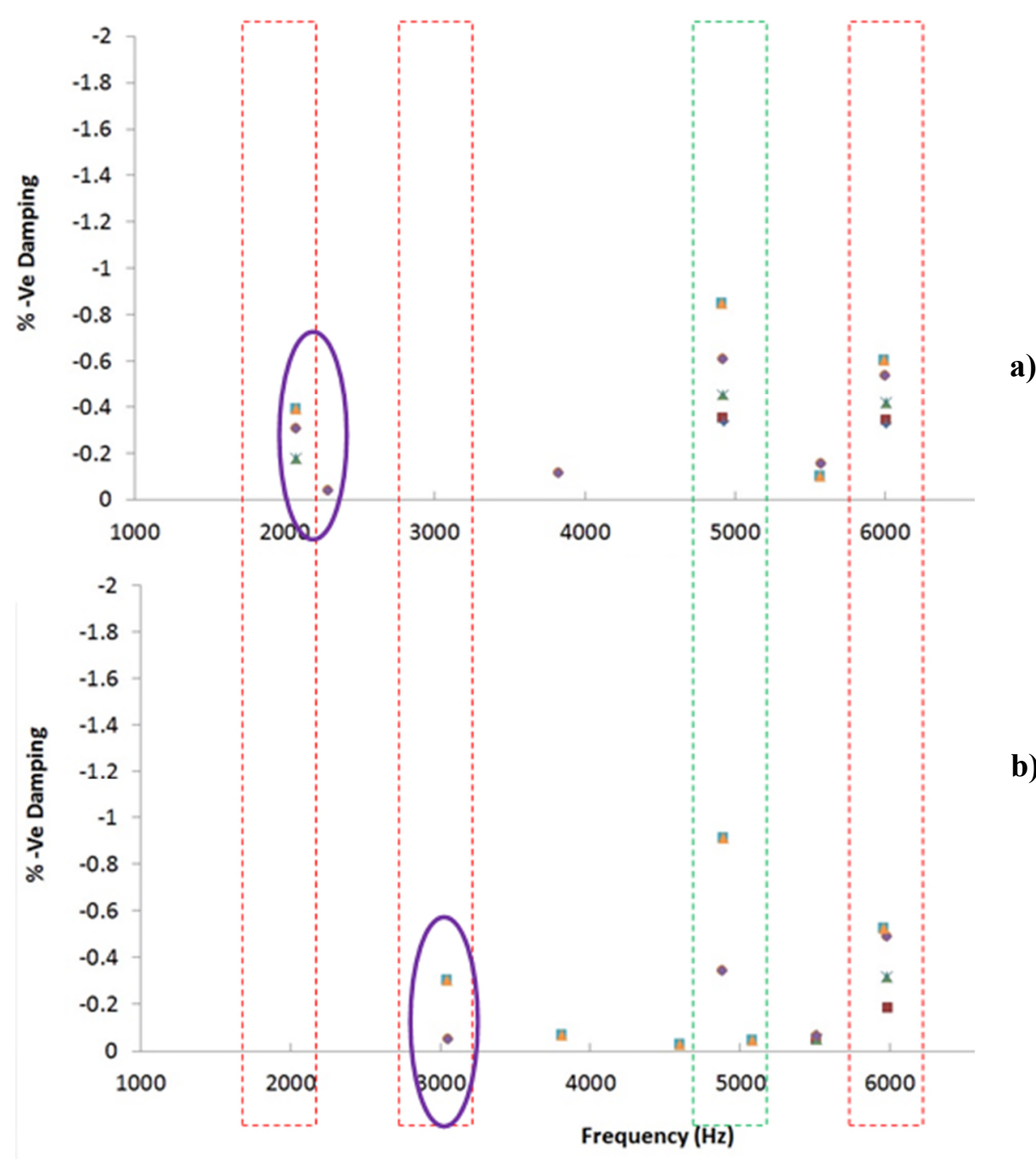

Figure 27: Complex Eigenvalue Analysis results: a) Without thermal mapping; b) With thermal mapping

\subsection{Stage 4: Summary}

The brake squeal propensity of the vehicle corner has been evaluated and natural frequencies and modes, instabilities and contribution factors predicted throughout a brake application. The final stage can be summarised as follows:

1. Results of the thermo-mechanical analysis have been saved in the output file;

2. The stability analysis can access those results at specific times during braking enabling the inclusion of thermal effects within the vibrational analysis;

3. The modes predicted by the isothermal case are also reflected in those modes determined by using the thermo-mechanical analysis;

4. The likelihood of the brake to generate noise can either increase or decrease with time, as consequence of the thermal load and related changes in interface pressure and coefficient of friction changes; 
5. Good correlation with experimental data (dynamometer tests) has been achieved.

\section{Conclusions}

In the work presented, an effective methodology for brake squeal propensity prediction has been developed. This approach, validated on actual brake and vehicle corner assembly, can be effectively used to generate new assemblies with much improved NVH characteristics, minimising the prototypes and reducing the costs.

The research established four clearly defined "stages" in conducting FE Squeal Analyses: Stage 1 deals with free-free modal characteristics of individual brake components and their material characteristics. Stage 2 combines individual parts, conducting Brake Assembly Mechanical Finite Element (FE) Analyses. Stage 3 concentrates on fully Coupled Thermo-mechanical FE Analyses, and the concluding Stage 4 focuses on Brake Assembly Stability Analyses and validations. These 4 Stages also enable clear relationships and the communication of data between the vehicle manufacturer and component suppliers, describing crucial input data, modelling procedures, outputs and results validation.

CAD models, FE mesh and elements type, contacts and boundary conditions proved to be crucial in obtaining reliable results. Time invested in carefully preparing all the data, parameters and models offers massive savings later, both in time and accuracy.

Replacing the "generic" material properties (taken from literature or databases with insufficient information) with values measured on the actual components significantly reduced the difference between FE and experimental results. The difference reduced from over $5 \%$ to only $1 \%$ just regarding the disc material Young's Modulus. Even more important are friction material properties, where anisotropic nature must be adequately modelled. DIC proved to be a powerful tool in conducting related measurements.

Validations showed that static disc/pad interface pressure distributions measured with Pressure Sensitive Papers were very similar to the ones obtained with the FE simulation, confirming the pressure peak values are moving towards the diagonal of the pad, instead of remaining concentrated near the piston-backplate contact region (result of the anisotropic nature of the pad friction material). DIC measurements of caliper displacements and strains provided an indirect validation of the pressure distributions, in addition to validating caliper deflections and strains, both in static and quasi-dynamic conditions.

Fully coupled thermo-mechanical model of the brake assembly gave a realistic insight into the brake assembly behaviour under operating conditions, providing temperatures, deformations and pressure distributions for stability analyses. Complex Eigenvalue Analysis Method used for stability analyses (with the sign of the real part giving an indication of stability and the imaginary part defining the frequency of the unstable mode) proved to be very effective, with the results correlating very well with dynamometer measurements of squeal propensity. Inclusion of thermal aspects is necessary for realistic prediction of actual braking duties. The likelihood of the brake to generate noise can either increase or decrease with time (during braking), for very 
similar conditions, as a consequence of the thermal load which directly influences component geometries, interface pressure distributions, material properties, coefficient of friction and wear pattern at disc/pad interface.

The suggestions to further develop the methodology for brake squeal propensity prediction can be summarised as follows:

- Friction material damping and wear should be introduced in the methodology and their effects investigated. Overall, the understanding of friction material properties remain the "weakest point" in all analyses. No doubt that in-service change of material characteristics are inevitable, with some changes being reversible and some not.

- Optical techniques have been used to exceptional effect. Digital Image Correlation (DIC) measurements and results were presented in some detail. However, this technique does not seem suitable for studying fully dynamic conditions (the actual braking), as it would generate too much data to be practically applied. Fibre Bragging Grating (FBG) sensors were used for measuring strains on friction material samples in compressive tests (in addition to strain gauges and DIC) and for measuring strains in pad grooves in proximity to the friction surface. The latter provided indirect validation of the interface pressure distribution in pad edges and was implemented in static and quasi-dynamic conditions. The results were exceptionally good and correlated well with FE predictions and DIC measurements. In this paper, due to the limited space, deeper analysis of all these results is not possible but the details are included in Vianello [34]. Without any doubt FBG sensors offer tremendous possibilities in studying strains and temperatures in brake components, in particular in pad friction material where the sensors can be imbedded either in existing pads or even during pad manufacture. This offers unique opportunity in monitoring variations in interface pressures and temperatures in dynamic conditions during braking.

\section{Acknowledgement}

The work presented here has been sponsored by Jaguar Land Rover (JLR) Company and the authors are most grateful for this support. The activities involved many colleagues, from the sponsoring company, Cranfield University and other institutions. It is difficult to mention them all but authors' particular thanks go to Professor Andrew Day from Bradford University for initiating, defining and leading this multi-university project. The work presented would have been impossible to conduct without help from colleagues from JLR, in particular Julian Oscroft in CAE work and Dermot Lynch with experimental part. Invaluable help was obtained from colleagues at Cranfield University - Professor Stephen James and Dr Ricardo Correia with FBG sensors, and Dr James Campbell with DIC measurements. Constructive support and contributions were also obtained from Dr David Bryant from Bradford University and Professor Huajiang Ouyang and PhD student Amir Nobari from Liverpool University. 


\section{References}

[1] N. M. Kinkaid, O. M. O'Reilly, and P. Papadopoulos, Review of automotive disc brake squeal, Journal of Sound and Vibration, 267 (2003) 105-166.

[2] H.R. Mills, Brake squeak, Technical report 9000 B, Institution of Automobile Engineers, 1938.

[3] R. T. Spurr, A theory of brake squeal, Proceedings of the Institution of Mechanical Engineers 1, 1961, $33-52$

[4] R.P. Jarvis and B. Mills, Vibrations induced by friction, Proceedings of the Institution of Mechanical Engineers, 1963, 178, 847-857.

[5] S.W.E. Earles, A mechanism of disc-brake squeal, Technical Paper 770181, SAE, Warrendale, PA, 1977.

[6] M.R. North, Disc brake squeal - A theoretical model, Technical report 1972/5, Motor Industry Research Association, Warwickshire, England, 1972.

[7] A. Felske, G. Hoppe, and H. Matthai, Oscillations in squealing disc brakes - analysis of vibration modes by holographic interferometry, Technical Paper 780333, SAE, Warrendale, PA, 1978.

[8] J. Fieldhouse, P.T. Newcomb, The application of holographic interferometry to the study of disc brake noise, Technical Paper 930805, SAE, Warrendale, PA. 1993.

[9] M. Eriksson, F. Bergman and S. Jacobson, Surface characterization of brake pads after running under silent and squealing conditions, Wear 232 (2), 1999, 163-167.

[10] F. Massi, O. Giannini and L. Baillet, Brake squeal as dynamic instability: An experimental investigation, Journal of the Acoustical Society of America, Volume 120, 2006, 1388-1398.

[11] P. Di Lisio, R. Parisi, J. Rieker, and W. Stringham, Brake noise resolution on the 1998 Mercedes-Benz M-Class, Technical Paper 982245, SAE, Warrendale, PA, 1998.

[12] M. Tirovic and A.J. Day, Disc brake interface pressure distributions, Proceedings of the Institution of Mechanical Engineers, Journal of Automobile Engineering, Part D, Volume 205, 1991, 137-146.

[13] J. Fieldhouse, N. Ashraf and C. Talbot, Measurement of the Dynamic Center of Pressure of a Brake Pad during a Braking Operation, Technical Paper 2006-01-3208, 24th Annual Brake Colloquium and Exhibition, SAE, Grapevine, Texas, 2006.

[14] A.R. AbuBakar, M.K. Abdul Hamid, M. Mohamad, A. Dzakaria, and B. AbdGhani, Numerical analysis of disc brake squeal considering temperature dependent friction coefficient, Jurnal Mekanikal, 22, 2006, $26-38$

[15] N. Ishii-Dodson, J. Thuesen and D. Eggleston, Analysis of the temperature dependence of different modes of brake squeal noise, Euro Brake 2012 Conference, Paper EB2012-TM-15, Dresden, Germany, 2012.

[16] M.Z. Hassan, P.C. Brooks and D.C. Barton, Thermo-Mechanical Contact Analysis of Car Disc Brake Squeal. SAE International Journal of Passenger Cars-Mechanical System, Volume 1, 2008, Issue 1, 1230 1239.

[17] M.Z. Hassan, P.C. Brooks and D.C. Barton, A Predictive Tool to Evaluate Disk Brake Squeal using A Fully Coupled Thermo-Mechanical Finite Element Model, International Journal of Vehicle Design, Volume 51, 2009, Nos. 1/2, 124-142. 
[18] M.Z. Hassan, P.C. Brooks and D.C. Barton, The evaluation of disc brake squeal propensity through a fully coupled transient thermo mechanical model, Proceedings of the Institution of Mechanical Engineers, Part D: Journal of Automobile Engineering, Volume 227, 2013, 361-375.

[19] S.W. Kung, K.B Dunlap and R.S. Ballinger, Complex eigenvalue analysis for reducing low frequency brake squeal, Technical Paper 2000-01-0444, SAE, Warrendale, PA, 2000.

[20] V. Magnier, J. Brunel, M. Duboc and P. Dufrénoy, Influence of Heterogeneous Contact between Disc and Pad on the Brake Squeal Noise, Technical Paper 2011-01-2360, SAE, Warrendale, PA, 2011.

[21] J. Brunel and P. Dufrénoy, Transient Analysis of Squealing Mode Selection in Disc Brake, Technical Paper 2008-01-2537, SAE, Warrendale, PA, 2008.

[22] F. Chen, J. Chern, and J. Swayze, Modal coupling and its effect on brake squeal, Technical Paper 200201-0922, SAE, Warrendale, PA, 2002.

[23] H. Ouyang, Q. Cao, J.E. Mottershead and T. Treyde, Vibration and squeal of a disc brake: modelling and experimental results. Proceedings of the Institution of Mechanical Engineers, Part D: Journal of Automobile Engineering, 217(10), 2003, 867-875.

[24] H. Ouyang, W. Nack, Y. Yuan and F. Chen, Numerical analysis of automotive disc brake squeal: a review. International Journal of Vehicle Noise and Vibration, 1(3-4), 2005, 207-231.

[25] F. Chen, Disc Brake Squeal: An Overview, Technical Paper 2007-01-0587, SAE, Brake Colloquium 2007, Detroit, Michigan.

[26] C. Kim and K. Zhou, Analysis of automotive disc brake squeal considering damping and design modifications for pads and a disc. Int. J Automot. Technol. (2016) 17: 213.

[27] M. Esgandari and O. Olatunbosun, Implicit-explicit co-simulation of brake noise, In Finite Elements in Analysis and Design, Volume 99, 2015, 16-23.

[28] M. Esgandari and O. Olatunbosun, Computer aided engineering prediction of brake noise: modeling of brake shims, Journal of Vibration and Control, Volume 22, Issue 10, 2347 - 2355.

[29] T. Tison, A. Heussaff, F. Massa, I. Turpin and R.F. Nunes, Improvement in the predictivity of squeal simulations: Uncertainty and robustness, In Journal of Sound and Vibration, Volume 333, Issue 15, 2014, 3394-3412.

[30] M. Tirovic, N. Sergent, J. Campbell, P. Roberts and R. Vignjevic, Structural Analysis of Commercial Vehicle Disc Brake Caliper, Proceedings of the Institution of Mechanical Engineers, Part D, Journal of Automobile Engineering, Volume 226, Issue 5, 2012, 613-622.

[31] G.P. Ostermeyer and M. Graf, Hot banding with oscillating radii: models including wear and temperature; Euro Brake 2012 Conference, Paper EB2012-IFD-04, Dresden, Germany.

[32] G.D. Liles, Analysis of disc brake squeal using finite element methods, Technical Paper 891150, SAE, Warrendale, PA, 1989.

[33] T.S. Shi, O. Dessouki, T. Warzecha, W.K. Chang and A. Jayasundera, Advances in Complex Eigenvalue Analysis for Brake Noise, 2001 Noise and Vibration Conference \& Exposition, SAE, Traverse City, Michigan.

[34] M. Vianello, Brake squeal propensity prediction methodology using complex eigenvalue analysis and including thermo-mechanical effects, PhD Thesis, Cranfield University, UK, 2015. 


\section{Methodology for predicting brake squeal propensity using complex eigenvalue analysis, including thermo-mechanical effects}

Tirovic, Marko

Sage

Tirovic M, Vianello M, Bannister P. (2019) Methodology for predicting brake squeal propensity using complex eigenvalue analysis, including thermo-mechanical effects, Proceedings of the Institution of Mechanical Engineers, Part D: Journal of Automobile Engineering, Volume 233, Issue 8, July 2019, pp. 2048-2073

https://doi.org/10.1177/0954407018765251

Downloaded from Cranfield Library Services E-Repository 